\title{
Structured Scans of Multistakeholder Platforms
}

1. General Observations

2. The Methodology

3. An overview of 38 agrifood MSPs
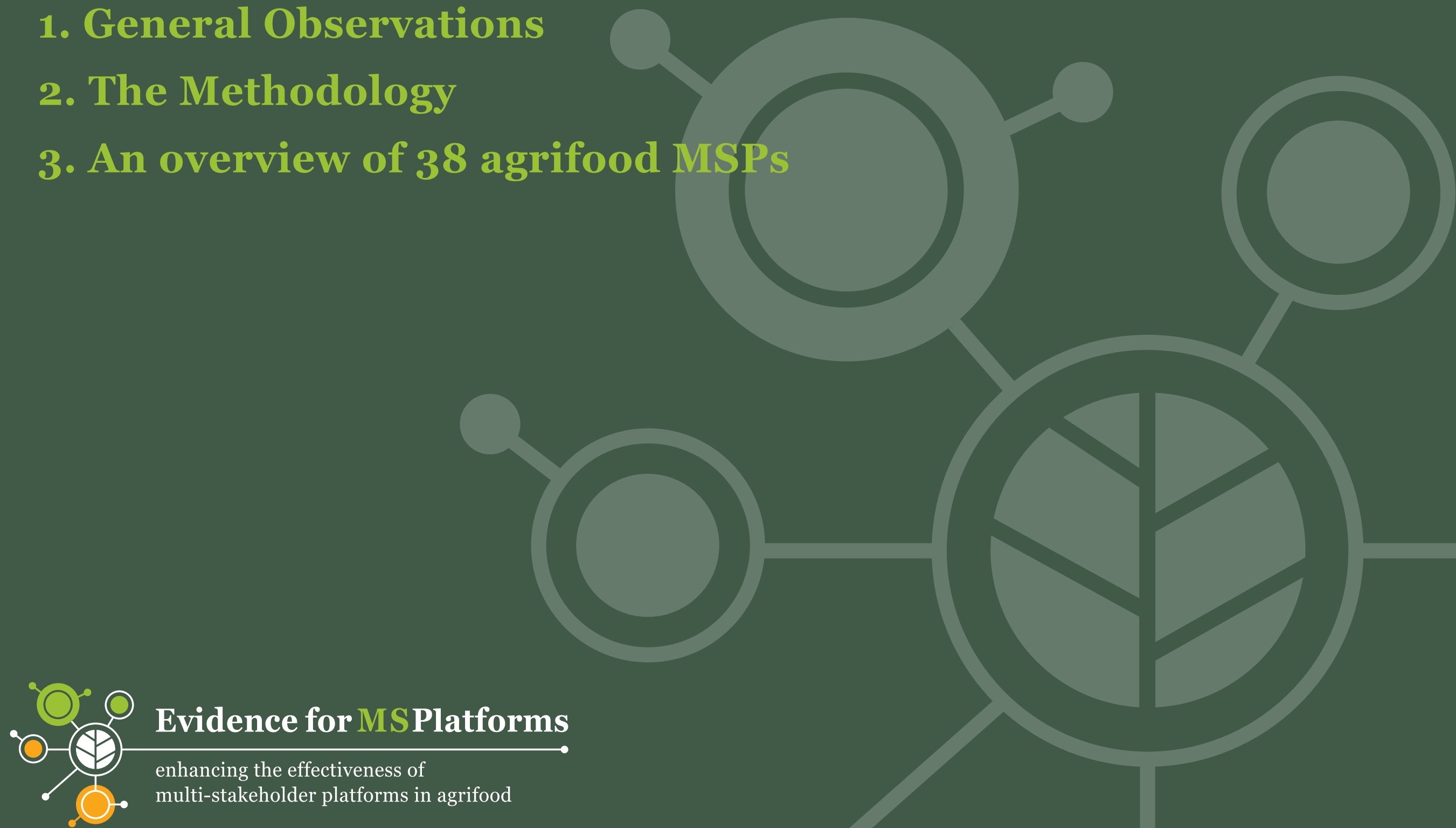


\section{Structured Scans of Multistakeholder Platforms}

\section{General Observations}

\section{Contents}

Why and how to assess MSP effectiveness

Stage 1: Structured Scans

Categorisation of MS Platforms

Initial observations from Structured Scans

Stage 2: Deep dives

Stage 3: Assessment design
1. General Observations

2. The Methodology

3. An overview of 38 agrifood MSPs 
$<$ contents

The complex challenges that the food and agriculture sector faces due to rapidly changing global demands and pressures calls for new, more effective responses. In response, over the past 10-15 years increasing effort has gone into collaborative action through multistakeholder platforms (MSPs), as many critical problems cannot be solved by a single actor. There is a matching need to say something about how these platforms contribute to inclusive and sustainable development, and to design better ways of assessing a platform's effectiveness.

MSPs often have broad goals, such as increased food productivity or reduced nutrition. Their pathways to change mean they are set up to create the conditions that stimulate and enable on-the ground action. These indirect contributions to intended changes at household or field level makes it very hard to attribute impacts to their activities and outputs. Many MSPs struggle to gather relevant and credible evidence and build plausible narratives of the effectiveness of their activities, which can inform strategy or investment decisions. Naturally, platforms do need to demonstrate their added value to members and funders. Regrettably, proof of value is often equated with detailed (quantitative) impact data while evidence of intermediate results related, for example, to behaviour change or to resource mobilization or coordination, are ignored. More appropriate strategies to capture robust evidence - i.e. structured, triangulated/ verified, not anecdotal only - would allow MSPs to show their results at intermediate stages, demonstrating a link between platform activities and their ultimate impacts. Such M\&E capability is generally lacking.
We define a multistakeholder platform (MSP) as an action-oriented collaboration between multiple private and public stakeholders, and possibly civil society members. MSPS seek sustainable solutions to complex and systemic challenges which no one party can achieve alone, catalysing multiple effects on a long-term or open-ended time horizon. We do not consider purely learning and knowledge networks. ${ }^{3}$

The 'Evidence for Multistakeholder Platforms' initiative aims to address this. It is an action research programme offering initial reflections on how effectively MSPs contribute to sustainable solutions to agrifood issues, and on identifying more appropriate approaches for assessing such effectivness.

Our aims are to:

- help platforms credibly assess their contribution, leading to their improved effectiveness;

- identify appropriate and plausible evidence and new approaches to assessing the effectiveness of MSPs; - support decision-makers with choices on strategic support for MSPs.
Our research involves three stages:

1. structured scans: mapping and categorizing of the 'universe' of multistakeholder platforms and the connections between them ${ }^{1}$

2. deep dives: working with selected MSPs to jointly research how a platform's intentions are reflected in its activities, leading through direct and indirect outcomes to impact, in relation to a platform's theory of change.

3. assessment design: facilitate exchanges between platforms and develop a generic, MSP appropriate approach to assessing effectiveness.

We focus on MSPs related to the food and agriculture sector that fit our definition. Their goals typically include structural transformations - such as changes in business climate, accepted norms for responsible investment or giving voice to unheard parties - that also support development goals, such as more jobs, better incomes, and improved food security and nutrition. Platform activities or functions (such as learning, mobilising funds, and accountability) often focus on enabling conditions that support others to undertake relevant action.

1] See Structured Scan o1 - An overview: https://tinyurl.com/ycgrk7me 2] The initiative is implemented by Wageningen Centre for Development Innovation , the Centre for Business and Development (Institute of Development Studies), Sustainable Food Lab, The Partnering Initiative and Ashley Insight, and is funded by the Rockefeller Foundation.

3] There is no common definition amongst platform members, stakeholders, and researchers for what a MSP is. The term is used for quite different entities. Our definition is to focus our research. 
$<$ contents

\section{The purpose of the structured scans is to:}

a) identify relevant platforms that meet our definition above;

b) systematically gather core data from them;

c) sketch out the underlying theories of change.

Initially 50 MSPs were identified in the food and agriculture sector, the majority of them operating in Africa or globally; 38 of the 50 proved to be workable ${ }^{4}$. How and on what basis we selected platforms is explained in our methodology document ${ }^{5}$.

The structured scans map public information about the platforms -mostly from their websites - against parameters defined in our Conceptual Framework. The framework considers the different levels of a platform's theory of change. It looks at how the vision of a platform (identified challenges and the intentions of the platform) cascades through the platform's implementation and value proposition (the arrangements and functions created within the platform itself), through to the activities and outputs of the platform and its members, through to the outcomes and the final change desired. The framework also looks at how the process is assessed and the learning from it gathered.

\footnotetext{
4] 12 were removed as they were no longer active, ultimately didn't fit our definition, or there was no information available on them. 5] Link to methodology document: https://tinyurl.com/ybygqnu4 6] The second stage of our research is a deep-dive process, see last page
}

\section{Each scan includes:}

- general information

- challenges to be tackled and platform

contribution

- intentions and aspirations

- arrangements and capacities

- activities and outputs

- M\&E frameworks

All scans can be found at

http://msplatforms.org/platform-quickscan/

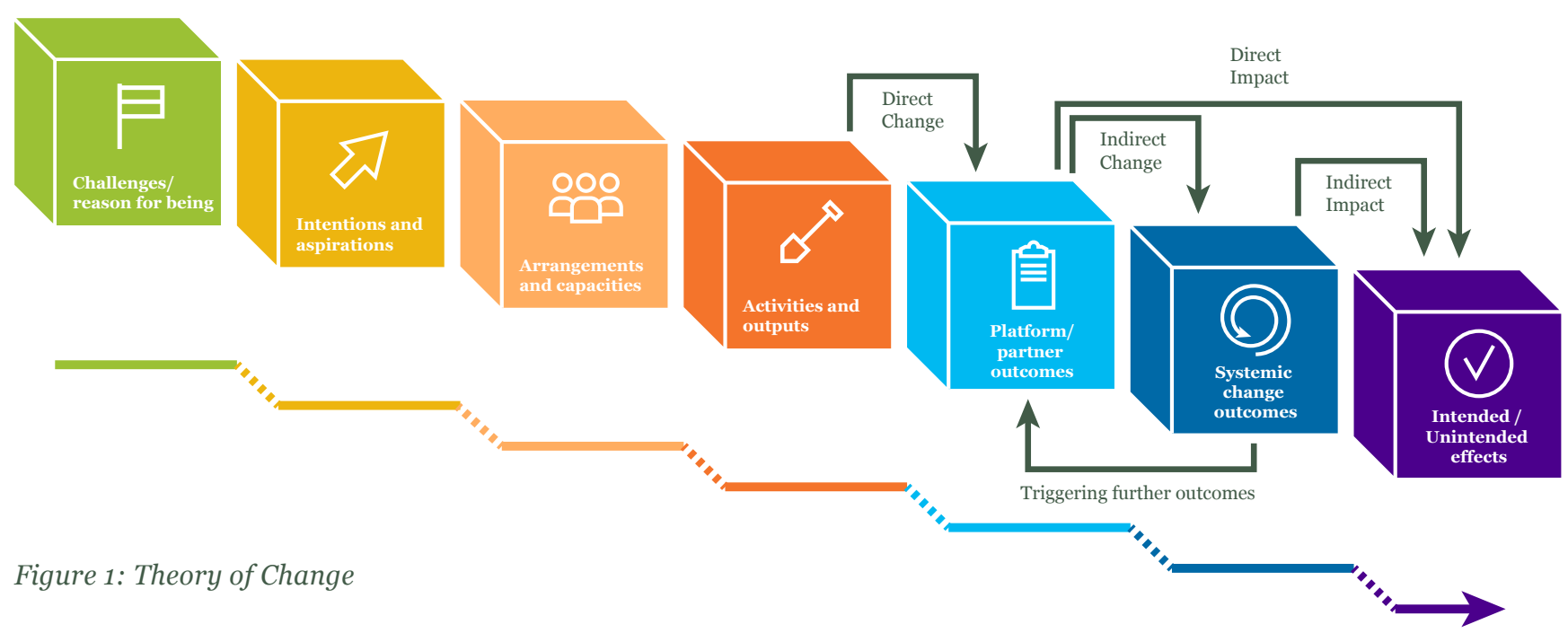

A scan tries to capture how the platform creates impact and the aspired value for society and nature. In many cases, though, detailed information is not publicly available. Understanding the pathways of change requires direct engagement with the platforms themselves ${ }^{6}$.

We gathered almost all information from platforms themselves, notably through main platform websites and their downloadable documents. 
$<$ contents

Most of the 38 platforms pursue similar goals using similar functions or activities. We identified six common goals, with four major functions or activities carried out by MSPs. All platforms include an element of policy advocacy as part of their overall approach.

The six major goals that platforms pursue are:

1. Transformation: to 'transform' a system towards a more inclusive and sustainable one within the food and agriculture sector (agriculture, food system, health and nutrition);

2. Productivity: to increase agricultural productivity in a more inclusive way; supply oriented;

3. Market development/farmer income: to boost market demand and smallholder farmer incomes;

4. Innovation: to introduce new, possibly disruptive elements or ideas that could contribute to system transformation;

5. Competitiveness: to improve the competitiveness of a specific value chain to increase smallholder farmers' incomes;

6. Responsibility: to promote changes in the behaviour or processes of the value chain actors.
The four core mechanisms or activities through which the platforms achieve these goals are:

\section{Brokering partnerships or} subsidiary platforms (multicountry) the platform believes in catalysing change by brokering or bringing new stakeholders together in an effort to improve coordination, create synergies and pilot solutions;

2. Promoting investment: the platform aims to create change by increasing investments, mostly in infrastructure or business development, creating public goods or lower risks for some commercial ventures;

3. Coordination of markets, value chains, and supporting services: improved coordination between actors along the value chain;

4. Sharing best practices/standards: all actors comply with a minimum set of behaviours, processes, or standards in the value chain, making it more inclusive or sustainable.
Our hypothesis is that the various platforms have different theories of change, based on the function or activity through which they seek to deliver change and the high-level goal or impact they are trying to achieve. This will affect the type of evidence they need to gather and narrative needed to demonstrate clear contribution to plausible enabling conditions.

We have identified four categories of platforms with a similar theory of change:

1. Transformation (regional/global): Transformation (in agriculture, food systems, health, and nutrition) through brokering partnerships and platforms in multiple countries;

2. Transformation (national):

Transformation (in agriculture, food systems, health, and nutrition) through promoting investment in business and infrastructure in one country;

3. Productivity Focus: Increasing agricultural productivity through coordination of markets, value chains, and supporting services;

4. Global Commodity Focus: promoting sustainability and development through coordinated sector strategy and standards.
We initially used criteria identified by ENGAGE7, another platform-focused research programme from the Rockefeller Foundation, for a first categorization of the platforms scanned. ENGAGE criteria are: orientation, alignment, size, purpose, geography, sector, leadership, and governance. All of the platforms we mapped are action-oriented, large in size, and with the aim of achieving long-term or systemic outcomes. However, they vary in geography, sector, leadership, and governance, as described below. 


\section{Initial observations from Structured Scans}

$<$ contents

This section presents our initial reflections on the nature of the platforms identified and their approach to evidence and effectiveness. With all caveats about limitations in available data and thus reliability of our limitations, we share these reflections in order to contribute to ongoing discussion and analysis.

\section{Growth of MSPs}

Our scanning process suggests the rapid growth of platforms between 2005 and 2015. Although some platforms focusing on standards, such as RSPO and World Cocoa Foundation started as early as 2000, MSP development blossomed between 2005 and 2012, both in number and in type of platform (see figure 4).

\section{Geography and focus}

Half of the platforms we identified work on a global level in different countries, while one in six work in different countries from the same region. One-third of them work in one country, of which again a third works in a subregion of a country and the remaining two-thirds on the national level. There is a roughly equal split between platforms that focus on one crop, multiple crops, or do not specify a crop focus.

\section{Arrangements}

The majority of the platforms (92 percent) operate through a secretariat with a more top-down leadership structure. Typically a central decision-making body (executive committee, steering committee, etc. $)^{8}$ sets the focus or framework that guides the participants' contributions to

the network. Many of these platforms depend on donor funding, as they do not collect any significant membership fees. However, they do draw heavily on the time and other resources of active members. These platforms have mostly been initiated by international partners, such as international donors or multinational companies, though there are efforts now to better engage national actors (companies and governments).

\section{M\&E approaches}

There is no harmonisation on what constitutes systematic evidence to monitor and evaluate platform impact, and a lack of data in general around platforms effectiveness. Of those platforms that do provide information, each platform uses different indicators to measure and report on their activities, outputs, and outcomes. Some rely on secondary evidence (e.g., national statistics), which may not be sufficient for them to assess their own effectiveness.

Figure 2: Geographic focus of MSPs

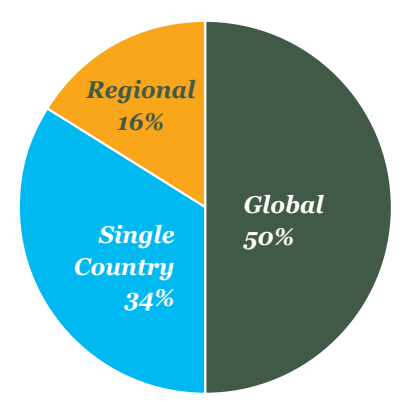

Figure 3:

Crop focus of MSPS

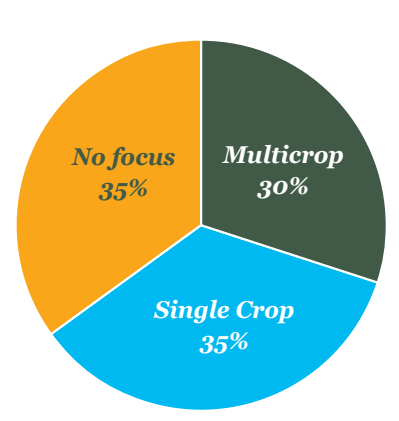

Others are beginning to invest in more robust surveys to gather outcome data; this should lead to the greater availability of evidence, while at the same time raising issues of resources and capacity to carry these out on an ongoing basis. In both cases, the monitoring and evaluation systems measure what happens at different levels of the Theory of Change, often those closer to the impact or goal. Yet the real "story" is missing: how are the levels connected? Only few narratives describe how processes and events link, for example, activities with outcomes.

Figure 4: Number of MSPs created every year
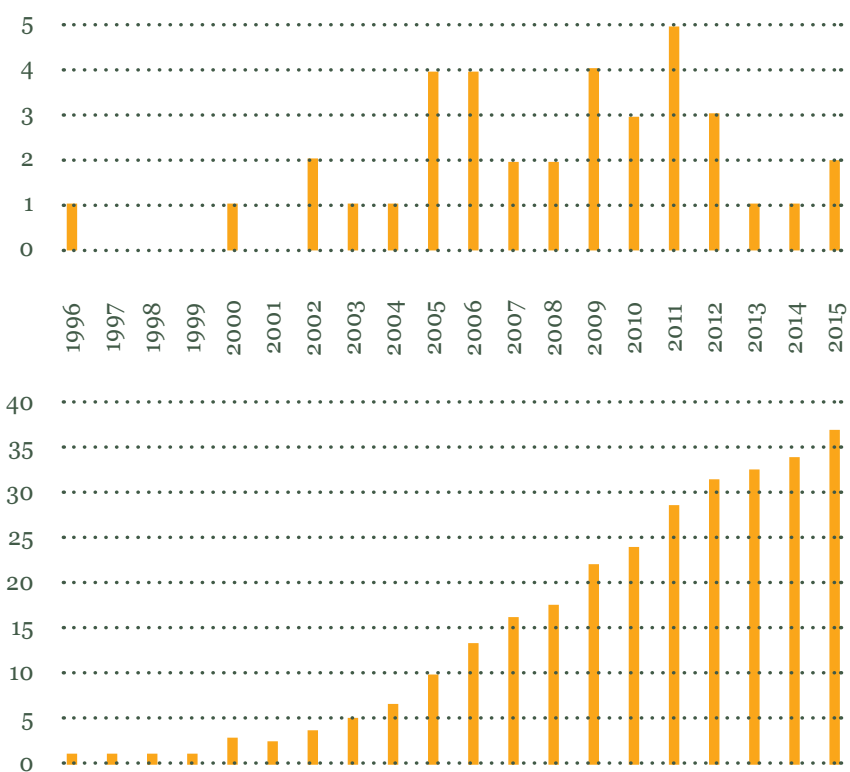

Figure 5: Evolution of MSPs creation 
We used the structured scans for an initial exploration of connections between a large number of these platforms, specifically looking at membership and leadership. An analysis along other parameters, such as platform activities and outputs, would be useful in the future.

We identified substantial overlap in membership between platforms, with certain donors and companies being centra to many of them. This includes individuals who are part of the governance of more than one platform. For example, Yara and Bayer are active private sector members in many platforms. DFID, USAID, and UN agencies are frequent core donors.

While the rapid growth in new platforms could suggest a rising global interest in this type of approach, our members analysis shows instead that the same or similar actors are becoming involved in multiple platforms. New platforms are thus not necessarily drawing in new actors. This may because of additional resources and leadership capacity of the lead firms and their centrality in the global food system. It can also mean there are relatively few key actors committed to a multistakeholder approach.
This has implications for understanding the effectiveness of MSPs as a way of tackling complex issues. In the end, only a few members may have influenced what many platforms do. Platforms may also be complementary, with their combined effect being bigger than the effect that each could have had independently. We therefore need to consider the effectiveness of a group of platforms, as well as individual platform performance. The same data can be relevant evidence for multiple platforms. For example, the changed policy of a particular company may be seen as evidence of effectiveness of more than one platform.

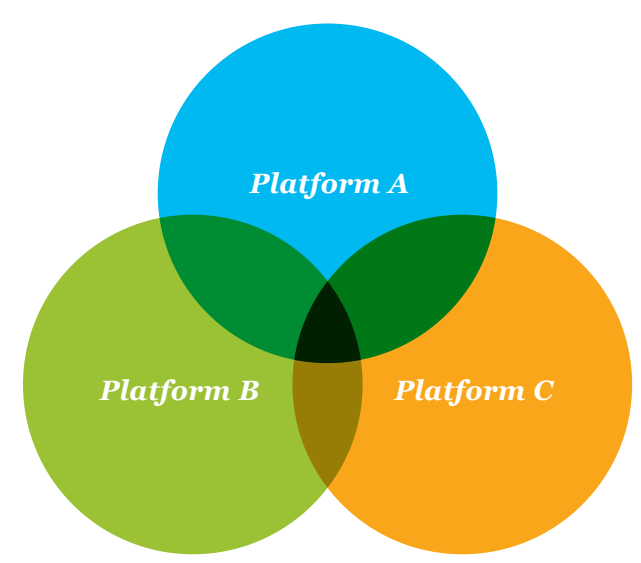

A network perspective further suggests that the four categories we identified may perform different functions in wider (system) change processes. A small and seemingly insignificant platform may turn out to be the breeding ground of innovative ideas, which, through shared membership, spread to other platforms that have more capacity for taking this to scale. Or the standard-setting of one platform may help to guide and direct efforts in another platform so that they work more towards sustainability and inclusiveness.

This is also relevant for donors who want to choose where to invest their support. A 'simple' comparing of platforms in terms of 'which ones are the most effective' may miss that they perform different and complementary roles. It may be necessary to support an 'ecosystem' of platforms, rather than only one or two.

\section{overlapping} membership

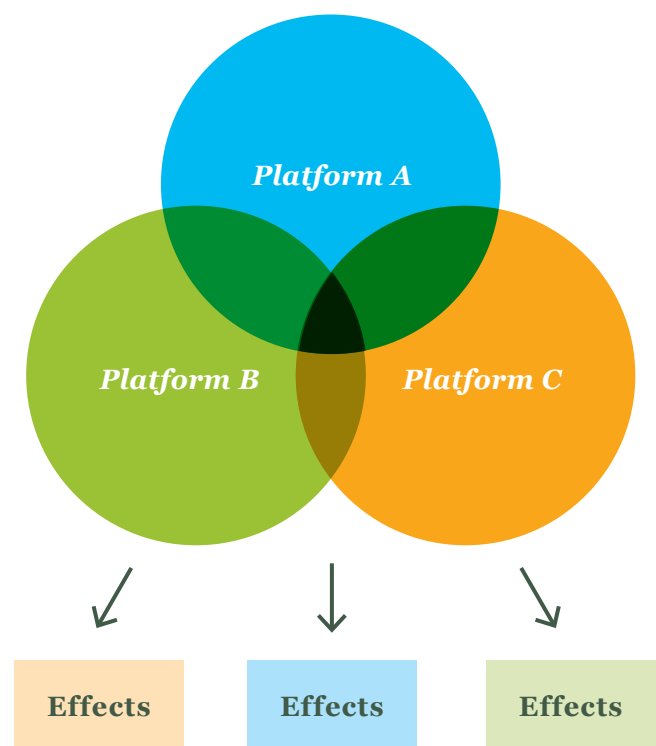


$<$ contents

The deep dives aim to get to the heart of the most important issues for our study:

to identify and test how relevant, credible evidence, drawn from existing information and (potentially) new approaches to filling gaps, can be used to understand platform effectiveness against the theory of change. They do not primarily gather data or measure impact.

Figure 6: Overview deep-dive process
Review docs and interviews to identify linkages/assumptions

Draft understanding of evidence of effectiveness

Test at workshop with country members

Review docs and interviews to identify linkages/assumptiond
They follow an action research logic, involving systematic enquiry and strategic engagement with platforms.

The aim is to explore assumptions, identify meaningful evidence and to use this evidence to support learning (what's working and what not), improve effectiveness, as well as to tell a 'plausible story'9 to stakeholders about the platform's contribution.
Articulate Theory of Change

Detail assumptions

Gather evidence

Construct story: what is evidence telling you?
Identify other evidence (available)

Identify other evidence (desirable)

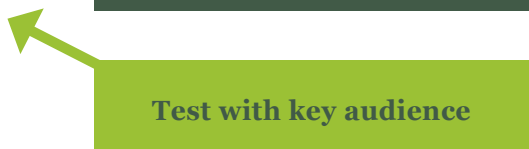

A joint process will work to:

1. Articulate the theory of change of how the platform intentions cascade through implementation and outcomes, along with underlying assumptions about linkages between each step.

2. Create clarity about what evidence is needed for which audiences.

3. Assemble what evidence is already available/accessible identify where there are gaps where more evidence is needed.

5. Describe how an appropriate evidence base would inform management decision making and relevant stakeholders.

6. Draw overall conclusions from addressing the above

One week fact finding and support in country

workshop with stakeholders
4. Assess the credibility of the package of evidence; and

9] A plausible story means credible evidence that demonstrates the likelihood of (rather than proves) a relationship between interventions and observed changes. Credible evidence does not imply quantitative impact dota or large-scale surveys. However, it requires reviewing available evidence to understand probable connections, and the appropriate depth of evidence to make a credible case for connections at different steps in the chain. 


\section{Stage 3: Assessment design}

$<$ contents

The overall methodology developed, with the experience and information gathered during the deep dives, will lead to a general approach to assessing the effectiveness of MS Platforms. This will probably include the following:

- Generic Theory of Change for MS Platforms

- Categorisation of MSPs, and significant differences in their theories of change

- Criteria for identifying appropriate evidence for different audiences

- Overview of specific evidence sources that might be appropriate for a specific MSP

- General comments on the effectiveness of MSPs, based on deep dive assessments

- Revised narratives of several MSPs on effectiveness (this will depend on the public or internal nature of these revisions)
The generic assessment process will be discussed with key donors and funding members of MSPs. As it is 'she who pays the piper who calls the tune', donors and funders have a very strong influence on how platforms currently report on what they are achieving. Donors and funders often require highly detailed, household level impact data, which might not be appropriate or reliable. In doing so, they inadvertently make it much harder for platforms to do demonstrate what they are achieving at the level of system change and influencing behaviour. If the discussion around the effectiveness and appropriateness of MSPs is to become more strategic, donors and funders must be willing to consider new ways of assessing platforms Equally, the reporting needs of these key financers must be fed by any new approach to assessing the effectiveness of multistakeholder platforms. 


\section{Structured Scans of Multistakeholder Platforms}

\section{The Methodology}

\section{Contents}

Introduction

Criteria and definitions

Structured scan: explanatory overview

General instructions

\section{Structured scan}

General information

\section{Why platform?}

Identified challenge and need for platform

\section{Platform for what?}

Intentions and aspirations of platform

\section{How platform?}

Arrangements and functions

Platforms doing what?

Activities and outputs 


\section{Introduction}

$<$ contents

The Evidence for Multistakeholder Platforms (MSPs) research program looks at evidence for and perceptions on how effectively multistakeholder platforms contribute to sustainable solutions for agrifood issues. At the start of the program, structured scans were carried out of existing platforms.

The purpose of the structured scans is to map the universe of existing agri-focused platforms to understand:

1. Basic theories of change (ToC)

2. Current approaches to monitoring and evaluation (M\&E) and evidence used

3. How effectiveness of platform is assessed against their ToCs

This document describes the structured process followed for each individual scan. It describes the criteria against which platforms were selected as well as definitions followed.

A spreadsheet template was carefully designed to capture key identifying features of the platforms studied. The template allowed consistent use by multiple researchers, leading to comparable information for further analysis.

Section 3 provides detailed information on each item in the template captured in the structured scans. This information was originally written as a manual how to follow the template designed. This style has been maintained so it can be used by anyone wanting to map further platforms. Should you do so, please do share your scans as we would welcome including them on our website.
For the reader who simply wants to understand the methodology followed, it is sufficient to focus on the definitions provided for each item. "How to" instructions can be readily skipped.

\section{Program logic}

The structured scans map the first part of the program's logical framework (see figure 1 on page 4 ). This framework shows an assumed flow from the challenge that has led to the creation of a platform, through the role of the platform to deal with that challenge, how it is then set-up to carry out its intended role and on through to intended and unintended system change and impact. Publicly available information only allows the scans to touch the first half of this flow: reason for being, role and setup. The scans do not capture the second part in any detail, namely the mechanisms through which it creates impact and the aspired value for society and nature. The second part of the research program works with five platforms to look at this in depth. Future work of the research program will give lead to better understanding of how MSPs work in practice, and the kinds of evidence that is needed to assess whether they are being effective at carrying out their intended role.

\section{Information sources}

All the structured scans map information presented by platforms themselves through readily available sources, notably main platform website and documents that can be directly downloaded from there. In the case the platform did not have a website, the main information source could have been a press release, or the main donor's website. For example, the Patient Procurement Platform (now Farmers to Market Alliance) was described on the World Food Programme website.

We do not include information from members' websites or from third party sources. As much as possible the structured scans avoid interpreting the information provided by the platforms, and seek to capture it as faithfully as possible. Text is copied or paraphrased, with clear reference to verifiable sources.

At the structured scan stage, the research focused on mapping and not analysis. Therefore the structured scans do not critique or analyse the platform theory of change, M\&E approach or evidence presented. They do not assess assumptions in the theory of change, quality of evidence provided or wider (positive or negative) impacts of the platform. Where the platforms themselves provided their own analysis it is reflected in the scans. 
$<$ contents

Several cycles of platform identification and selection led to the final shortlist of platforms for which structured scans were made. 50 platforms were selected that were thought to meet the following criteria. For 38 full structured scans could be completed, the others either did not prove to meet criteria or there was insufficient information available.

\section{Criteria}

Food and/or agriculture focus Does the platform focus on addressing challenges and achieving outcomes in agrifood value chains?

Open-ended or long-term time horizon Is the envisioned platform collaboration open-ended - i.e. without a specific end date which would be more typical of a project or programme; or alternatively, does it have a long-term (a decade or more) time horizon?

Multiple government and private sector members Does the platform have two or more members from the public sector and two or more members from the private sector?

Action oriented Does the platform seek to catalyse action - usually in terms of business investment, policy change or new initiative - i.e. avoiding collaborations and networks focused only on learning or knowledge exchange? Target systemic challenges Does the platform seek to catalyse solutions to systemic challenges - in other words, challenges that are long-term, complex and which require a combination of approaches to solve? Complex problems are influenced by many actors, and their multiple interactions affect outcomes in unpredictable ways.

Catalytic Does the platform seek to catalyse multiple initiatives, such as policy change, increased investment and partnerships, which are beyond the direct actions of the platform?

\section{Definitions}

We use the following definitions in defining the research focus and in describing research results.

Multi-stakeholder platform We define a multistakeholder platform (MSP) as an action-oriented collaboration between multiple private and public stakeholders, and possibly civil society members. MSPs seek sustainable solutions to complex and systemic challenges which no one party can achieve alone, catalysing multiple effects on a long-term or open-ended time horizon. We do not consider purely learning and knowledge networks.

Theory of Change A theory of change makes explicit presumed cause-and-effect changes that lead to how a system will function in the future, including desired outcomes and impacts. Each outcome is tied to one or more activities, with an often-complicated web of activities needed to deliver the change. The most important outcomes of change generated are not likely to be the direct effect of a specific activity, but rather wider changes in the system or. A theory of change should also capture thinking and assumptions on how change will happen.

(Platform) Secretariat A "secretariat" loosely designates the platform leadership, structures, administration and direct activities. It is distinct from the individual leadership, structures, administration and activities of platform members or participants. In some cases, platforms may have an actual secretariat, with dedicated offices and staff. However, in others there may be a much smaller and/ or more informal structure such as a coordination team, possibly housed in a larger institution.

(Platform) Members or participants Throughout this document we use the term "member" to designate the direct participants in the platform, who commit to the aims of the platform and invest time, effort and often funding towards these aims. Some platforms may use other terms - e.g. participant or even partner to refer to what this document calls members. 


\section{Structured scan: explanatory overview}

$<$ contents

The entire following section gives details on how the structured scans were built from a common spreadsheet template. These details are written as instructions for any who may wish to use the spreadsheet to easily follow the same process for additional platforms. A definition is given for each item in the spreadsheet, which makes clear what the central question is of that item as well as specific instructions how to answer the question. Practical guidance is given what to look for; this is not exhaustive but is to trigger a researcher's creativity.

The spreadsheet template can be downloaded here: > Excell template, https://tinyurl.com/yazgghllk

\section{General instructions}

- Add the name and logo of the platform, location, name of researcher and date at the top of the spreadsheet. Add also the main source used for the scan (in most cases this will be the main platform website)

- In response to each question in the methodology, select relevant text from platform documents and website, and paste into excel sheet under "Platform Information" (column F).

- Researchers will need to exercise judgement in responding to the sections. The aim is to capture enough information to paint a clear picture of platform scope, purpose and function, but not necessarily to capture every detail. It is important to be clear where information is taken verbatim, and where it is altered, and to have a clear source to go back to full data if needed.

- The "What to look for" guidance in each sub-section of the methodology is NOT intended to be a prescriptive list or set of categories. Rather it is intended to help point the researchers to where the relevant information might likely be found on a platform website.

- If no information can be found for an item (ie row in the spreadsheet), please add n/a in Column F. Most platforms will have $\mathrm{n} / \mathrm{a}$ in at least some of the cells. Researchers should not try to fill all the cells with data but to accurately reflect what is reported by platforms, including indicating where no relevant information is presented.
- In Column G, please summarise the response from Column $\mathrm{F}$ in 50 words.

- Include the source where data came from in Column $\mathrm{H}$. Add either the link to webpage or name of document, to allow others to trace back to it, including specific details such as date accessed, or page numbers for documents in Column I.

- Where clarifications or comments are needed - for example if the researcher has found conflicting information, or believes that there is a further story beyond the publicly presented information, these should be included in the 'Researcher Comments' column (Column J).

- Please use "direct quotes" to indicate text that has been copied directly. However, where the response to a specific question is lengthy, then it is acceptable to paraphrase/ summarise, as long as there is a clear reference to the original source(s), so that the full information can be easily located if needed. 
$<$ Website

Summary Description (one line)

Definition: Please summarise in one line what is the objective of the platform, in terms of goal, geography, crop (if appropriate) and membership.

\section{What to look for:}

- Short statement on homepage of website or the "About Us" page

- Where a succinct summary is not available, researches would compose this based on their understanding of the platform scope and objectives.
Duration/maturity

Definition: This question captures the length of time the platform has existed, in number of years. In most cases this will be a simple statement of the year the platform started and a calculation of the number of years it has been in existence, and wherever possible responses should be quantitative. However, there may be some cases where platforms have merged and morphed over time, where such as simple statement is not possible. In this case a short description of the evolution of the platform and key dates over time is also acceptable.

What to look for:

- Date started

- "History" or "Timeline" section

\section{Crop/(s)}

Definition: This question helps to define the scope of activity of the platform. Some platforms will be very specific in their crop focus (e.g. "cashew"), while others may have a broader scope ("horticulture"). In still other cases, platforms will have no specific crop focus at all and will instead address other issues (food security) which cut across a number of crops. The researcher should capture the appropriate crop(s), or indicate, "no specific crop focus". Where some crops are listed, researcher should be sure to ensure whether the list is exhaustive or indicative.

\section{What to look for:}

- Crop(s) indicated in the platform name

- Crop(s) described in the About Us section

- Activities
Geographic scope of the platform

Definition: This question helps to define the scope of activity of the platform. Some platforms will be very specific in their geographical focus (e.g. specific country), while others may have a broader scope ("Africa"). Often this scope will be indicated as part of the name, "Grow Africa". In some cases, platforms may be global and have no specific geographical focus. The researcher should capture the country(s) or region(s) where the platform intends to operate or indicate, "no specific geographical focus". Where some countries or regions are listed, researcher should be sure to ensure the list defines the scope of platform activity (e.g. African Cashew Initiative), rather than the main countries of activity.

For example, Roundtable on Responsible Soy (RTRS) may focus on Brazil and a handful of major soy producers, but is not limited to this scope - any country that produces soy could be included. So the answer for
RTRS would be "no specific geographical focus". Note that the scope may be sub-national - e.g. SAGCOT focuses on the southern corridor of Tanzania.

\section{What to look for:}

- Country or region indicated in the platform name

- Country or region described in the About Us section

- Activities 
Definition: This question indicates where the platform is currently active. In some cases, this will be the same as the scope, e.g. the Ghana Grains Partnership has Ghana as its scope and also where it is currently active. However, in other cases, the platform may be active only in some areas that are part of its potential scope. For example, the New Alliance for Food Security and Nutrition has Africa as its scope, but is currently active in 10 countries in Africa, and not the whole continent. Often the current geographic activity is found in a list of countries or regions. Note that the area of activity may be sub-national - e.g. SAGCOT

work in the southern corridor of Tanzania.

\section{What to look for:}

- Country or region described in the About Us section

- List of partner or member countries

- Activities
Private sector members

Definition: The aim is to identify all the private sector members of the platform by name. However, where the list is longer than 10-15, then it would be better to describe the private sector members (how many and what type of companies) and add a link or other source in order to access the full list. Where platforms do not list their members, then a description should be developed based on interpretation from the website and other relevant materials.

\section{What to look for:}

• "Who Are We"

- Membership section

- List of registered members

- Membership type

- List of members of working groups or other committees can also shed light
Definition: The aim is to identify by name all the specific governments, governmen agencies or government ministries that are members of the platform. Care should be taken to only list members and not government bodies that the platform engages with or partners with as an external entity. Where the list is longer than 10-15, then it would be better to describe the government members (how many and what type) and add a link or other source in order to access the full list. Where platforms do not list their members, then a description should be developed based on interpretation from the website and other relevant materials.

\section{What to look for:}

- "Who Are We"

- Membership section

- List of registered members

- Membership type

- List of members of working groups or other committees can also shed light
International/Regional Donors and Agencies

Definition: The aim is to identify by name all the donors and multi-lateral agencies that are members of the platform. This may include bilateral donors, multi-lateral donors, the World Bank, UN agencies or other regional or international development agencies. Many, though not all, will be funding agencies. Care should be taken to only list members and not agencies that might collaborate with the platform or provide funds for specific activities but which are not members. Where platforms do not list their members, then a description should be developed based on interpretation from the website and other relevant materials

\section{What to look for:}

- "Who Are We"

- Membership section

- List of registered members

- Membership type

- List of members of working groups or other committees can also shed light
Civil Society / NGOs members

Definition: The aim is to identify by name all NGOs and civil society organisations that are members of the platform.

This may include international or local organisations (but not farmers' associations, as these are listed separately). Care should be taken to only list members and not organisations that are implementing partners but not members. Where platforms do not list their members, then a description should be developed based on interpretation from the website and other relevant materials.

\section{What to look for:}

- "Who Are We"

- Membership section

- List of registered members

- Membership type

- List of members of working groups or other committees can also shed light 
Definition: The aim is to identify by name all farmers' organisations that are members of the platform. This may include producer organisations, as well as umbrella associations of farmers.

Care should be taken to only list members and not organisations that are implementing partners but not members. Where platforms do not list their members, then a description should be developed based on interpretation from the website and other relevant materials

\section{What to look for:}

- "Who Are We"

- Membership section

- List of registered members

- Membership type

- List of members of working groups or other committees can also shed light
Expert / Technical / Research members

Definition: The aim is to identify by name all expert organisations that are members of the platform. This may include researchers, technical experts and academic organisations, for example (though not NGOs and civil society organisations, which may also provide expert input but which are not primarily technical or research bodies).

Care should be taken to only list members and not, for example, organisations that are external advisors but not members. Where platforms do not list their members, then a description may be developed based on interpretation from the website and other relevant materials.

\section{What to look for:}

- "Who Are We"

- Membership section

- List of registered members

- Membership type

- List of members of working groups or other committees can also shed light

\section{Other members}

Definition: This section captures any other members that do not fit under one of the other headings. Care should be taken to only list members and not partners that are external to the platform.

\section{What to look for:}

- "Who Are We"

- Membership section

- List of registered members

- Membership type

- List of members of working groups or other committees can also shed light
Funds committed (per member if available)

Definition: In this section we are looking for quantitative and ideally disaggregated information on the amount of financial support (amount of money) which has been pledged by individual members of the platform - usually the private sector and donor members where available. The aim here is not so much to capture how much money the secretariat has mobilised (this is covered under section 3 ), but rather a picture of individual member contributions. Ideally this information will be disaggregated, though in some cases only aggregated information is possible. Where the list is longer than $10-15$ members' contribution, then it would be better to describe the funds committed (how much and by what type of members) and add a link or other source in order to access the full list.
Some platforms do not involve specific financial commitments by members, in which case the response should be "none".

\section{What to look for:}

- Financial commitments

- Letter of Intent or Agreement documents

- Evaluation documents

progress against commitments 
Funds spent (per member if available)

Definition: In this section we are looking for quantitative and ideally disaggregated information on the amount of funds which has been disbursed by individual members of the platform -

usually the private sector and donor members - where available. This may be expressed in an amount of money, or a $\%$ of the commitment. Ideally this information will be disaggregated, though in some cases only aggregated information is possible. Where the list is longer than 10-15 members' disbursements, then it would be better to describe the funds disbursed (how much and by what type of members) and add a link or other source in order to access the full list.

Some platforms do not involve specific financial commitments by members, in which case the response should be "none".

\section{What to look for:}

- Evaluation documents / progress against commitments
Other relevant information

Definition: This section captures any further general information regarding the platform which seems crucial in understanding the size, scope, reach or other basic characteristics of the platform that might influence its effectiveness.

\section{What to look for:}

- Any general information regarding platform scope that doesn't fit under other headings in section 3 
$<$ Website

This section sets out the key data which positions the platform in relation to a challenge(s) and/or an agenda.

What is the challenge/ problem the platform wants to address?

Definition: Given the high commitment of time and energy required to implement platforms, it is assumed that platform members would not come together in this way if there were not a clear need. This question asks for an articulation of the major problem or challenge or failure faced by the country, sector, commodity etc that is the target of the platform. By understanding the platform's definition of the problem, we are better able to understand the motives that lie behind platform goals.

Note: Some platforms may not set out the problem explicitly, and only provide their goals and objectives (from which their definition of challenges could be deduced). Researchers should focus on capturing the problems set out by the platform, or - if some interpretation of the platform statements into an articulation of the challenge would be helpful - it should be clear that these are interpretations.

\section{What to look for:}

- Explanations of the rationale behind the platform vision and goals

- Problem statements

- Need statement

- Problems outlines in relevant (policy) agendas linked to - e.g. CAADP, SDGs
What is the value added of the platform?

Definition: This question seeks to understand (from the perspective of the platform), why a platform involving a mix of stakeholders is the best way address the challenge/problem articulated. Why this challenge is not being/cannot be adequately addressed by individual actors or existing groups of actors. The purpose of the question is to understand the perceived value of the platform, versus other forms of arrangements or solutions.

What to look for:

• "Value proposition"

- Explanation of the roles or resources contributed by different actors towards the solution

- Explanation of failed approaches in the past
Who started the platform?

Definition: This question asks for the name of the organisation or organisations that led the initial development of the platform, where available. This information can help in further understanding what was the original challenge that the platform perceived and set out to address, how the challenge is framed or defined, and by whom.

\section{What to look for:}

- Description of the origin in a 'history' section

- List of founding members
Other background information about the creation of the platform

Definition: This section captures any further information regarding the initial development of the platform, in order to better understand the original challenge that the platform perceived and set out to address.

\section{What to look for:}

- Any information regarding the origin of the platform that doesn't fit under B.2 or B.3

Other relevant information

Definition: This section captures any further information regarding the articulation of the problems and challenges faced and why current solutions are ineffective and therefore platform approach can make a difference.

\section{What to look for:}

- Any information regarding problems and challenges that doesn't fit under other headings in section 3 
$<$ Website

This section is about the role that the platform is intended to play and the difference it is intended to make.

Platform's Mission and/or Vision

Definition: An overarching, topline statement of what the platform is trying to achieve across its lifetime. This is the highest level statement of the platform's intentions, against which effectiveness could be evaluated.

What to Look for, e.g.:

- Mission statement

- Blueprint

- "The difference they want to make"

- Overarching framework that guides platform activities

- May include vague or generic statements, e.g. support SDGs
Key Objectives or Goal(s) of the Platform

Definition: Long-term goal(s) which contribute to the overarching mission or vision of the platform. Some platforms may articulate different types of goals - which may include long-term impacts and shorterterm and more direct outcomes. However, they should articulate broad goals and not outputs or activities, and should be general across the platform (i.e. not just apply to one member). These may be measurable, though do not necessarily need to be. They represent a rearticulation of the overarching mission and what the platform is trying to achieve.

\section{What to look for:}

- Intended "goals" or "objectives" - "The difference they want to make" section

- General goals linked to "transformation" or "food security”, for example, which seek broad-based benefits for a sector, region or population
Values and Principles

Definition: This questions seeks to identify any values, principles, norms of behaviour, etc, which articulate how the platform is intended to work and how the members of the platform are expected to behave as they implement their commitments or agreed activities. It asks for an articulation of principles and norms ("how") and not about activities ("what").

\section{What to look for:}

- Espoused values or principles of platform

- Code of conduct and or principles that all members sign up to
What is the public good the platform wants to contribute to?

Definition: By public good we refer to the general (rather than economic) meaning of public good - these are outcomes that result in shared benefit amongs various (though not necessarily all) actors in society. For platforms these refer to outcomes that benefit not only its various members but also have wider societal value. These may include outcomes that are traditionally considered public goods in the economic sense - such as a clean environment, public infrastructure or education - but are not limited to this definition and may include improved access to nutritious food. The value of capturing this information is to better understand the impact the platform is trying to achieve and whether these are explicitly intended to include broad societal outcomes (versus societal benefits that occur but which are unintended positive spillovers). It is possible that not all platforms have public good objectives. They may have goals that aim to deliver benefit across their members (though value chain coordination or improved productivity) without necessarily seeking more generalised benefits for society. It is important that this section is left blank if the platform is not explicit about public goods objectives, or if researchers add their own interpretation here, this should be made clear

\section{What to look for:}

- Terms such as "shared value", "shared benefit"

- "The difference they want to make" section

- Goals such as improve food security, reduce poverty and ensure environmental sustainability. 
Target group

Definition: This sections asks about the intended beneficiaries of the platform. The target groups may include both platform members, and other stakeholders that are not part of the membership. They may be defined in terms of populations, sectors, types of companies, etc. Responses in this category should set out who these beneficiary groups are, as defined by the platform, and how each group relates to the platform (e.g. based on the outcomes they will achieve and/or how they participate in the platform). The aim is to help understand the intentions of the platform not only in terms of quantitative outcomes, but who is intended to benefit from these outcomes.

\section{What to look for:}

- Explanation of who will have access to improvements created by the platform - e.g. infrastructure

- Numbers of beneficiaries as part of objectives - e.g. 100,000 smallholder farmers; 500 SMEs

\section{Strategies/Approach}

Definition: This is a topline statement of "how" the platform intends to achieve its goals. In other words, what innovation the platform is bringing in terms of arrangements or activities that will allow it to overcome the challenges/problems articulated and achieve the change it is seeking. This is the highest level statement of the organization's strategies.

\section{What to look for:}

- An early summary - usually in the executive summary, value proposition or frontpage of the website, of how the platform

will achieve its goals.

- "How we work" section

- An explanation of how the platform will bring together its different members in pursuit of its goals

\section{Other}

Definition: This section captures any further information regarding the intentions and aspirations of the platform.

\section{What to look for:}

- Any information regarding vision, goals, values, beneficiaries or topline strategies that doesn't fit under other headings in section 3 
$<$ Website

This is about the way in which the platform is set up, its organisational forms, structures and key processes, and its governance

Board (or equivalent)

Definition: The purpose of this section is to identify the toplevel leadership, according to the platform. Who is responsible for setting or guiding platform priorities and overall strategy, listing individuals as well as their organisations. This will often be a Board of Trustees or Board of Directors. However, the leadership may take other forms, such as informal leadership councils.

\section{What to look for:}

- Board leadership

- Leadership Council
Governance structures and key members

Definition: This section identifies the other bodies (apart from the Board) or functions within the platform that are empowered to advise on or make decisions regarding the platform. This includes the overall secretariat, as well as any supporting structures, such as working groups or advisory committees. Responses should describe the structures and the membership - either by listing actual committee members and chairs of committees, or summarising the number and types of organisations represented, as well as the key responsibilities of each structure.

\section{What to look for:}

- Secretariat structure, location and executives

- Internal or External Advisory committees, membership and terms of reference

- Working groups addressing specific issues or aspects of the platforms, membership and terms of reference

- Stakeholder representation on these bodies
Organisational structure

Definition: This section sets out the organisational structure of the platform - how it is set up to implement decisions made.

This includes the organisation of the secretariat, as well how members relate to the secretariat. Responses should describe the structures and the topline responsibilities for major roles within the structure.

\section{What to look for:}

- Organisational charts for secretariat

- Organisational charts or diagram sketching out the platform members and how they relate to the secretariat and each other

- Diagram or summary of different levels or types of membership
Structure and content of membership requirements

Definition: This section captures the structure and key content of any written agreements between the members and the platform, such as a memorandum of understanding, or between individual members in the platform, such as letters of intent by individual governments or companies. These are unlikely to be formal contracts, but they should have a formality that general communications (website, brochure, reports) do not. The main audience of these documents are likely to be the parties to the agreement, but they may also be publically available for purposes of transparency and accountability. It will also indicate membership fees, where applicable.

\section{What to look for:}

- "Membership Requirements" - Formal documents, such as letters, MoUs.

- Reference to formal documents, such as letters, MoUs - even if these are not publicly available.
Secretariat role

Definition: This section describes the role of the secretariat within the platform and the boundaries of that role (what the secretariat will not do). The purpose is to try to understand the respective roles and contributions of the secretariat (versus the platform members) in achieving the vision and objectives of the platform. This is distinct from question 3.4.1 which is more about listing the activities of the secretariat.

\section{What to look for:}

- Description of secretariat functions

- Size of secretariat 
Financial support (secretariat)

Definition: This sections sets out the main sources of central funding for the platform secretariat to carry out its activities. This funding may come from governments, from membe companies and/or from bilateral or multi-lateral donors. It does not include investment funds that the secretariat administers, or other financing by members

- e.g. donor or company investment for specific purposes, e.g. a piece of infrastructure. The response will capture which bodies provide the funding for the secretariat, as well as (ideally) the amount of funding received.

\section{What to look for:}

- A list of funders or references to "funders"

- Representation on the Board of Trustees, where this is based on funding relationships
Funds disbursed by secretariat

Definition: This sections sets out other funding that the platform manages or controls, which is disbursed to third parties, such as challenge funds or catalytic funds. This funding may come from governments, from member companies and/ or from bilateral or multi-lateral donors. It focuses on funds that the secretariat will disburse or use to catalyse further investment and does not include direct donor or company investment (ie which is not administered or managed by the secretariat). The response will capture which bodies provide the funding, as well as (ideally) the amount of funding received.

\section{What to look for:}

- A list of funders or references to "funders"

- Source funding for financing mechanisms (e.g. challenge funds or catalytic funds) controlled by the secretariat
Other relevant

information

Definition: This section captures any further information regarding platform arrangements and capacities.

\section{What to look for:}

- Any information regarding platform arrangements and capacities that doesn't fit under other headings in section 3 


\section{Platforms doing what? Activities and outputs}

$<$ Website

This is about what the platform essentially does and delivers. It focuses on both the activities that the secretariat directly performs and those which the secretariat mobilises from amongst its members. For example, a certain type of research or tool might be commissioned by the secretariat and this might be provided by one of the members. It could also, for example, include interactions and plans of platform members that are developed in the context of a platform workshop. It would not include private sector investments (e.g. in a factory) which might be the outcome of the platform activities but is not a direct output.
Core activities

Definition: This section provides a high level overview of what the secretariat does on a regular basis to support the platform as a whole (rather than specific products and services in the next 2 questions). This may include awareness raising, representation of its members on other bodies, mobilising new members, catalysing funding, etc. Where there is a long list of activities, researchers may group and summarise (though indicating where this is the researcher's interpretation).

\section{What to look for:}

- Activities involving awareness raise and the platform 'brand' - Activities involving mobilisation

(of members, funds)

- Activities involving

representation of the platform

in other fora

- Activities involving enforcement

(e.g. of commitments,

principles)

- Key administrative activities
Core products

Definition: This section identifies specific products that the platform produces, which may be used by one or more of its members and stakeholders. For example, this may include communication and knowledge products, such as research and tools, or financing products such as a technical assistance facility.

\section{What to look for:}

- Research and tools

- Financing mechanisms administered by the secretariat
Core services

Definition: This section identifies specific services that the platform offers, which may be used by one or more of its members and stakeholders.

\section{What to look for:}

- Training and capacity building

- Information services (e.g.

around land availability

investment showcases)

- Brokering functions (e.g.

between specific members, rather than in relation to the platform as a whole)

- Advice and analysis
Other relevant information

Definition: This section

captures any further information regarding platform activities and outpus.

\section{What to look for:}

- Any information regarding activities and outputs that doesn't fit under other headings in section 3.4 


\section{Monitoring \& Evaluation approach}

$<$ Website

This is about how the platform tracks performance and effects. Monitoring and evaluation processes aims to assess current platform performance in terms of outputs, outcomes and/or impact in relation to goals, and to improve management of the platform through learning and feedback provided. Processes may be set up primarily to response to government and donor requirements, although (modified) processes can also be understood as a crucial part of company and platform management and decisionmaking.
Approach to/plans for M\&E

Definition: This section seeks to identify the intentions of the platform regarding M\&E plan. This may include an overarching M\&E plan and/or whether it requires any formal $M \& E$ from members. The aim is to try to understand what information the platform is trying to capture that contributes to (a) assessment of effectiveness and (b) improved management. It may also include, for example, services or financing that the secretariat provides in order to enable (better) M\&E by members.

\section{What to look for:}

- M\&E Plan

- M\&E requirements of members - Requirements to report on key performance indicators
Actual M\&E performed

Definition: This section seeks to understand what type of M\&E (if any) the platform has performed and/or has been performed by members in relation to platform activities. The question looks for a statement that assessment(s) have taken place, as well as other relevant details (when, by whom, scope). Where the assessment is publically available, a link or reference to the source document should be provided, so that that could be followed up in future; however, the question does not ask for the results of the assessment(s).

What to look for:

- Statement that M\&E is

performed by platform and/or members

- Information on the parameters of the assessment(s)

- Evidence that the assessment(s) has/have actually taken place

(e.g. M\&E reports)

- Logframe

- Results chains
Use of M\&E input in decision making or learning

Definition: Where an M\&E assessment has taken place, this section seeks to understand whether any of the findings have influenced decision-making or led to adaptations in platform processes and design, either at the level of the platform or its members. These are likely to be in the form of statements identifying key challenges or key learnings and how the platform or its members have responded. The aim is to try to understand whether M\&E is being used to contribute to improved platform effectiveness.

\section{What to look for:}

- Key learnings

- Key challenges

- Strategy updates
Other relevant information

Definition: This section captures any further information regarding monitoring and evaluation.

\section{What to look for:}

- Any information regarding M\&E that doesn't fit under other headings in section 3 


\section{Structured Scans of Multistakeholder Platforms}

3. An overview of 38 agrifood MSPs

\section{Contents}

Introduction

26

Enhancing the effectiveness of

multistakeholders platforms: structured scans 


\section{Enhancing the effectiveness of multistakeholder platforms:} structured scans

The Evidence for Multistakeholder Platforms (MSPs) research program looks at evidence for and perceptions on how effectively multistakeholder platforms contribute to sustainable solutions for agrifood issues.

This document summarises 38 selected MSPs through under a structured scan ${ }^{3}$ process. These structured scans provide core data about the platforms, which allows systematic comparison. This makes it possible to sketch out the theories of change that underpin the platforms or groups of platforms. It also allows readers to place a specific platform within a 'universe' of platforms all aiming to contribute to more sustainable and inclusive agrifood sectors.
Initially 50 MSPs were identified in the food and agriculture sector, the majority of them operating in Africa or globally; 38 of the 50 proved to be workable. ${ }^{2}$ Our definition of MSPlatforms used for making our selection is given in the box. How and on what basis we selected platforms is explained in our methodology document.

The scans include general information, challenges to be tackled and platform contribution, intentions and aspirations, arrangements and capacities, activities and outputs, and the M\&E frameworks.
We gathered almost all information from platforms themselves, notably through platform websites and their downloadable documents. At times when a platform did not have a website, the main source may have been a press release or the main donor's website. The quantity of information available for the platforms ranges from little more than a press release, to an active website with detailed information.

We did not include information from websites of platform members or from third party sources. In this publication we focus on mapping and providing a descriptive analysis only. The structured scan does not critique nor analyse a platform's theory of change, M\&E approach, or the evidence presented. We also do not assess the assumptions behind a theory of change, the quality of evidence provided, nor the broader (positive or negative) impacts of the platform.

A multistakeholder platform (MSP) is an action-oriented collaboration between multiple private and public stakeholders, and possibly civil society members. MSPs seek sustainable solutions to complex and systemic challenges which no one party can achieve alone, catalysing multiple effects on a long-term or open-ended time horizon. We do not consider purely learning and knowledge networks.

1] Link to methodology document: https://tinyurl.com/ybygqnu4 2] The process began with 50 platforms, but 12 were removed as they were no longer active, they didn't fit our definition, or there was no information available on them.

3] For more information, visit www.msplatforms.org 
(1) African Cashew Alliance (ACA)

(2) African Fertilizer and Agribusiness Partnership

(3) AgriProFocus (APF)

(4) Bagre Growth Pole Project

(5) Beira Agricultural Growth Corridor

(6) Better Cotton Initiative (BCI)

(7) Better Rice Initiative Asia (BRIA)

(8) Bonsucro

(9) Botswana Agriculture Hub

10 Business Alliance Against Chronic Hunger (BAACH)

(11) Competitive African Rice Initiative (CARI)

12 Competitive Cashew Initiative (ComCachew)

(13) Cotton made in Africa (CmiA)

(14) Ghana Commercial Agriculture Project (GCAP)

(15) Ghana Grains Partnership

(16) Global Alliance for Improved Nutrition (GAIN)

(17) Global Coffee Platform

(18) Global Shea Alliance (GSA)

(19) Grow Africa
(20) Grow Asia

21 Malawi Agricultural Partnership (MAP)

22 New Alliance for Food Security and Nutrition

(23) New Vision for Agriculture (NVA)

(24) Partnership for Indonesia's Sustainable Agriculture (PISAgro)

(25) Patient Procurement Platform

(26) Prolinnova Kenya

(27) ProRustica

(28) Prosavana

(29) Round Table for Responsible Soy (RTRS)

(30) Round Table on Sustainable Palm Oil (RSPO)

(31) Scaling Up Nutrition (SUN)

(32) South Agricultural Growth Corridor of Tanzania (SAGCOT)

(33) Sustainable Rice Platform

(34) Tanzanian Agricultural Partnership

(35) The Global Forum on Agricultural Research (GFAR)

(36) Tropical Forest Alliance 2020 of Tanzania

(37) World Cocoa Foundation (WCF)

(38) Zambia Business in Development Facility (ZBiDF) 


\section{(1) African Cashew Alliance (ACA)}

\section{(㝵) \\ General Information}

Crop: Cashew

Geographic Scope: Africa

Initiated in 2006

A platform established by

African and international

businesses to promote a global competitive African cashew industry; present in 11 African countries.

Active Countries:

Nigeria, Ghana, Ivory Coast,

Mozambique, Senegal,

Tanzania, Kenya, Burkina

Faso, Gambia, Benin, and

Guinea Bissau

\section{Members:}

Private sector $(63 \%$; acting as the core of the platform and ranging from traders and processors to buyers, transporters, consultants, exporters, and others), 12 government bodies, civil society (3 NGOs), farmer associations (4 cashew associations), research and other organizations (2 research institutes and the

Trade and Development

Group from The Netherlands)

\section{Identified Challenge}

Processing of African cashews remains low

The African Cashew Alliance began as an alliance of African and international businesses with the common goal of promoting African cashews globally.

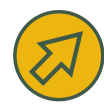

Intentions and Aspirations

To increase the

processing of cashews, to improve competitiveness and sustainability, and to facilitate public-private cooperation of the

cashew sector in Africa.

The African Cashew Alliance envisions the African

cashew industry as globally competitive and benefitting everyone involved in it,

from the farmer to the

consumer. Their mission

is to support the industry

via technical assistance and

facilitating investments,

promoting market linkages

and international standards,

as well as sharing information

and best practices. It

targets a variety of groups,

depending on the projects,

including West African

cashew processors, shea

farmers, those involved in

the shea value chain, cashew

processing managers, staff,

and small-scale cashew

farmers.

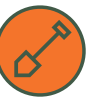

Activities and Outputs

The platform is governed by an executive committee

(EC), giving the platform

strategic direction and general

guidance, while also providing

oversight to (i) the ACA

secretariat, (ii) the advisory

board, (iii) the steering

committee, (iv) the national

committees or national

private cashew business

associations, (v) and the ACA

members (public and private).

The secretariat manage

program development and implementation, and oversees

the daily operation of the

platform, including project

management, membership,

and fundraising. Moreover,

information on all the ACA's

members is collected in

order to ensure exclusive

market intelligence for their

businesses.
Arrangements and Capacities

The core activities, products, and services are available to members of the platform.

These include annual events such as the ACA World Cashew Festival and Expo, annual reports and expert publications on the cashew industry, market information systems, quality sustainable seals, technical assistance for processors, investmen support, and access to finance.
Monitoring and Evaluation

No information available 


\section{(2) African Fertilizer and Agribusiness Partnership (AFAP)}

\section{(㝵) \\ General Information}

Crop: None

Geographic Scope: Africa

Initiated in 2003

Through collaboration with the public and private sectors, the African Fertilizer and Agribusiness Partnership invests in fertilizer markets in order for smallholder farmers to grow food and increase their profit.

Active Countries:

Ghana, Mozambique,

Tanzania, Ethiopia, and Malaw

\section{Members:}

Private sector (businesses), international and regional agencies (the New Partnership for Africa's Development (NEPAS), the Alliance for a Green Revolution in Africa (AGRA), the International Fertilizer Development Center (IFCD), the Agricultural Market Development Trust (AGMARK), and Africa Fertilizer)
Low farm productivity, food insecurity

AFAP is an independent nonprofit created by a partnership between African development organizations building on the Comprehensive Africa Agriculture Development Program (CAADP). The platform brings together the expertise and perseverance of the public and private sector, as well as industry and development interests, in order to increase the agricultural output in Africa and reduce food insecurity, while also supporting African smallholder farmers.

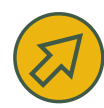

Intentions and Aspirations

To promote less costly fertilizers to enable

an increase in crop production and rural incomes

The AFAP initiative aims to allow for public-private dialogue, as well as actions to scale up the distribution and supply of fertilizers within the region. The platform's mission is to provide quality, time-efficient fertilizers by

developing medium-scale fertilizer and agribusiness enterprises. The goal of the platform is to increase fertilizer users by $15 \%$, and to distribute fertilizer through 500 APCs within the COMESA region.

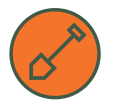

Activities and Outputs

A board of trustees with extensive experience with smallholder farmers governs the platform. Other key members include a presiden and $\mathrm{CEO}$, a vicepresident, a director of program AFAP regional directors, a director of finance, a West Africa regional business development manager, a program development specialist, and an executive manager. Moreover, numerous conferences and meetings are held and press releases allow communication within the platform.

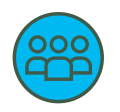

Arrangements and Capacities

The platform provides Agribusiness Partnership Contracts (APCs) to smallholder farmers and gives assistance in this; ensures fertilizer distributors for retailer credit; finances assistance for importers and blenders to improve facilities, training, and logistics support; provides help with warehouse at ports and inland; and assists with retail improvements (i.e., storage facilities and equipment). 


\section{弇 General Information}

Crop: All agricultural products, including dairy and meat

Geographic Scope: Global

Initiated in 2005

AgriProFocus promotes

agricultural entrepreneurship in low and middle-income

countries, through an

international network

entailing Dutch roots in the

Asia and African region.

Active Countries:

Benin, Burundi, Ethiopia,

Indonesia, Kenya, Mali, Niger,

DR Congo, Rwanda, Tanzania,

Uganda, Zambia, and The

Netherlands

Members:

Private sector (agribusiness

companies such as Bejo,

Heineken, and Rabobank),

government members (CBI

Ministry of Foreign Affairs of

The Netherlands, Netherlands

Enterprise Agency, Scope

Insight, SNV, Ministry of

Economic Affairs of The

Netherlands, and the Ministry

of Foreign Affairs of The

Netherlands), international

donors (Fair and Sustainable,

Heifer, Hivos, IFDC, OIKO,

Credit, OxfamNovib,

Solidaridad, the Hunger

< Overview all MSP's

Project, Woord en Daas, and ZOA), partners (Global Coffee Platform), farmer organizations (Agriterra, FrieslandCampina, and Icco Cooperation), and expert and research members from Dutch Universities.

\section{目 Identified} Challenge

\section{World hunger and} malnutrition

By sharing the lessons learnt from The Netherlands' experience, regarding joint action and learning in close proximity, the platform enables strong networks between farming, business, civil society, politics, science, and technology. direct business opportunities and policies to enable environmental approaches through policy development and advocacy.

To facilitate networ development and coordination, business and partnership brokering, innovation communities, and platforms for debate and learning

The platform's vision is to provide food and nutrition security to nine billion people by 2050 via entrepreneurial farmers in the agribusiness sector worldwide. The key principles of the platform are applied to all country networks, and include:

(1) Strong embedding in national contexts,

(2) Knowing the needs of the members, partners, and clients, creating added value through cocreation, working with multistakeholders.

(3) Operating as entrepreneurs with a focus on joint resource mobilization.

This is achieved through the

'Management Partnership and Network' strategy,

which strongly emphases a decentralized bottomup approach, with a focus on service delivery to an international network of members, business deals, and private sector, and
(2) Activities and Outputs

The platform is governed by a board (including the ministries of foreign affairs and economic affairs) and consists of a participants' council and board members. For each country network, there are country coordinators, assistants, and a network facilitator based in the APF support office in Arnhem. rrangements and Capacities

The platform provides core activities, products and services, including countrybased support teams, and an overall support team in The Netherlands that runs the networks. Moreover, the platform provides country networks, which are shared assets, for contributing networking professionals and Dutch partnership members. Moreover, APF allows

members to access useful local contacts, market products, discuss policy issues, and highlight members' innovations. Moreover, the platform connects members to agribusiness professionals, brokers new partnerships and collaborations, cocreates innovative solutions to agribusiness challenges, and provides a space to share ideas, knowledge, and business innovations.
Monitoring and Evaluation

In order to identify M\&E activities, the platform measures its success through market uptake, which looks at how stakeholders use their network results to the benefit of agricultural entrepreneurs through indicators such as partnership deals, innovations, and policy changes. 


\section{圊 General Information}

Crop: Rice, maize, and vegetables

Geographic Scope:

Burkina Faso

Initiated in 2015 (expected completion 2020) The Bagre Growth Pole Project aims to sustainably boost agricultural productivity, output, and income.

Active Countries:

Burkina Faso

Members:

International and Regional donor agencies (World Bank and the African Development Bank)

\section{曰 Identified Challenge}

Poverty and limited agricultural sector

The project, initiated by the African Development Bank Group, aims to tackle poverty issues, as $43.9 \%$ of the total population and $50.7 \%$ of the rural population live below the poverty line. In addition to this, subsistence farming and poor diversification, coupled with high costs and limited infrastructure, limit the potential of the agricultural sector.

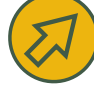

Intentions and Aspirations

\section{Boost agricultural}

infrastructure

development, value chain development, and project management

The platform's mission is to create sustainable economic growth that acts as a catalyst to the Burkina Fasan nationa economy. It focuses on three types of target group: (1) small farmers, (2) young agricultural operations, and (3) private operators. The public good to which the project aims to contribute is the improvement of agricultural infrastructure and capacity-building for farmers and development stakeholders, which will reduce poverty, promote youth employment, decrease social disparities, and contribute to the fight against climate change. The project follows the ADB's strategies, focusing on key infrastructure development, good governance and private sector development, inclusive growth, food security, and regional integration.

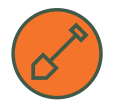

Activities and Outputs

The Bagrepole Board of Directors acts as a project steering committee and governs the platform. Moreover, there is a specialized team for the implementation of the Bagre Growth Pole Project, including a general manager, a director of economic development,

a land management officer, an environmentalist, a monitoring and evaluation expert, and others.

Additionally, the secretariat distributes the funds of the platform to three key areas:

(1) agricultural infrastructure development, (2) development of value chains, and (3)

project management.
Arrangements and Capacities

The project offers agricultural infrastructure development (consisting of extension of the irrigation infrastructure, rehabilitation of existing infrastructure, production storage and marketing infrastructure, extensions to the primary canals and surge tanks, rehabilitation of the irrigation area, and warehouses and postharvest infrastructure) and value chain development (including boosting the production and productivity of small farmers, supporting agricultural entrepreneurships, and access to quality inputs through a range of core products)
M\&E activities are conducted by the M\&E services of

Bagrepole, with external M\&E being conducted by the department responsible for the implementation of projects, in association with representatives from the directorates in charge of design studies and planning of the Ministries of Agriculture, Water Resources, Livestock, and the Environment.

External M\&E is reviewed biannually and the project is audited annually. 


\section{骨) \\ General Information}

Initiated in 2010

The Beira Agricultural Growth Corridor (BAGC) was created in order to promote investment in commercial agricultural and agribusiness within the Beira Corridor (Tete, Sofala and Manica Provinces), Mozambique.

Members and Funds: The platform consists of partnerships between the Government of Mozambique, private investors (international and regional private sector members from financial institutions, investment companies, trading and energy sector), farmer organisations and international agencies (including Alliance for a Green Revolution in Africa, Department for Internationa Development, International Finance Corporation, Helett Foundation, Norfund,

The Norwegian and Dutch Embassy in Mozambique, SNV, World Bank and Young Africa).

If the BAGC blue print is achieved an investment by the public and private sector of $\$ 1.7$ billion will generate annual farming revenues of
$\$ 1$ billion and will stimulate investment along the entire value chain. More specifically, The Norwegian Embassy in Maputo has committed $\$ 1,850,000$ to InfraCo and AgDevCo for the BAGC initiative, where as DFIF has provided a grant of $£ 6,500$,000 through AgDecCo. The Dutch Embassy provided $\$ 10$ million to the Cayalytic Fund and BAGC Partnership.

\section{Identified Challenge}

The BAGC initiative commenced at the World Economic Forum in Davos. The platform acts as a focal point for creating partnerships between the stakeholders mentioned in section A.

The Beira Corridor shows a lot of potential in agricultural production, however there is lack of infrastructure and use of arable land for agriculture. Moreover, the platform identified four key issues that need to be overcome in order for sustainable commercial agricultural development in this region including; appropriate financing mechanisms, invest ment in productive infrastruc ture, strong commitment from stakeholders, and effective mechanisms for coordination and implementation of investments.

\section{Intentions and} Aspirations

The BAGC initiative aims to boost agricultural productivity in Mozambique and in the wider region. More specifically, it intends to boost sustainable commercial agricultural development, targeting farmers especially smallholder farmers. The platform's mission/ vision is to; ensure coordination between the public and private sector along the value chain, leveraging existing investment, developing new infrastructure and commercially viable agricultural projects, supporting services especially production inputs, financial services and extension services and supporting investment to provide a suitable business environment for investors who are interested to engage with small/ medium sized farming.

\section{Activities and} Outputs

The Board of Directors of the platform aims to represent the BAGC initiative with the help of the secretariat developing concrete actions and plans ${ }^{2}$.
The platform is governed via two institutional pillars; where one pillar constitutes of the BAGC Partnership, managed by a full-time Secretariat, and the second pillar, the BAGC Catalytic Fund, managed by AgDevCo on a costrecovery basis. Both pillars aim to take forward the BAGC initiative.

The BAGC Partnership is registered as an Association under the Mozambican law.

The Partnership is composed of: (1) Central and local Mozambique government agencies, (2) An international consortium of private sector companies, (3) Local private sector actors including national and district-based farmers' organizations, input companies and stockists, finance institutions, field projects and programmes, and, (4) NGOs and private sector service providers.

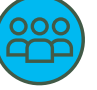

Activities and Outputs

The main services the platform provides with the use of the private sector for enhanced productivity and investment of the Beira Corridor, is the Catalytic Fund and the Smallholder Facility.

The Catalytic Fund supports early stage businesses to kick start commercially- viable agriculture. The business must ensure that it directly benefits smallholder farmers and

local communities. It aims to demonstrate that a profitable agricultural business is possible with social benefits.

The Smallholder Facility supports the implementation of practices and initiatives that leads to the development of sustainable and replicable models of smallholder market inclusion. Grants will be given to those that "one off" investment that is used to address constraints enables smallholder farmers to increase their incomes in a sustainable way without the need subsidies.

The role of the Secretariat is to act as a coordinating body regarding operational support for partnerships and bringing together stakeholders, Moreover, it lobbies government and development partners in order to address key constraints, implements programmes funded by development partners, advises the Catalytic Fund on use of funding for smallholder farmer development programmes and monitors and evaluates the impact of BAGC (including investments by the Catalytic Fund)

Monitoring and Evaluation 


\section{6) Better Cotton Initiative (BCI)}

$<$ Website

\section{(旬) \\ General Information}

Crop: Cotton

Geographic Scope: Global

Initiated in 2005

Created as part of the WWF 'round table' discussion,

the Better Cotton Initiative aims to make global cotton production better for those who produce it and to ensure an environmentally friendly and a prosperous future for the sector. Moreover, brands, retailers, and international donor organizations fund a combination of projects on a global scale.

Active Countries:

Brazil, India, Mali, Pakistan,

China, Mozambique,

Tajikistan, Turkey, Senegal, Kenya, Zambia, Zimbabwe, Tanzania, Malawi, Ghana,

Ethiopia, Ivory Coast,

Cameroon, Burkina Faso,

Australia, USA (expected to

expand to South Africa)

\section{Members:}

Private sector (54 retailer and

brands, 682 suppliers and

manufactures), civil society members (28) and producer organizations (30).
Identified Challenge

Poor environmental management, working conditions and unstable markets for cotton production

The Better Cotton Initiative, initiated by a group of visionary organizations that came together to create a practical solution to ensure a sustainable future for the cotton industry. This platform adds the value of the cooperation of multistakeholders.

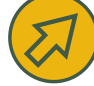

Intentions and Aspirations

Better Cotton will account for $30 \%$ of global cotton production by 2020

The platform intends to assis farmers in growing cotton in a sustainable manner, as well as to improve the livelihoods of farming communities. It does so by bringing together aspects of the cotton value chain in order to create a global community. The Better Cotton Initiative ensure better cotton is produced by farmers, who: (i) minimize the harmful impact of crop protection practices, (ii) use water efficiently, (iii) care for the soil, (iv) conserve natural habitats, (v) care for and preserve the quality of the fiber, and (vi) promote decent work.

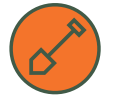

Activities and Outputs

The platform is governed by a CEO, supported by a team of directors and a general assembly that includes all BCI members and elects a council to represent it. The secretariat's main role is to act as a 'guardian' of the standard and ensure that there is correct implementation, credible data collection, and quality training; it also provides some other enabling functions. The secretariat's function is funded mainly through membership fees, grants from public funding sources, and service fee charges from other areas. rrangements and Capacities

The platform's main activities allow for the connectedness of people across the cotton sector. Additionally, it provides research reports on evidence of the impact of $\mathrm{BC}$ annual and harvest reports, events, and online/offline training, as well as a set of member-only resources.
Monitoring and Evaluation

To develop common solutions for M\&E, BCI cooperates with the Aid by Trade Foundation and CmiA. 


\section{(高) \\ General Information}

The Better Rice Initiative Asia (BRIA) was created in 2012 in order to foster cooperation between the private and public sector to promote sustainable growth in agricultural production, as well as improving access to nutrition. The platform is based in the South East Asia (SEA) region, more specifically, Indonesia, the Philippines, Thailand and Vietnam with the intention to last until 2017.

Members and Funds:

The platforms include members from the private sector including BASF, Bayer CropScience, Royal DSM, Yara, Olam and Deutche Bank.

Moreover, the platform is an umbrella project of the German Food Partnership (GFP), where other national agencies such as the Thai Rice Department, the Philippines Department of Agriculture, the Indonesian Ministry of Agriculture, and the Vietnamese Ministry of Agriculture and Rural Development. Finally, although there are no specific names of farmer's organisations, it I s clear that farmers are involved due to the infographics describing the types of farmer's organisations that can be found on their website.

\section{(日) Identified Challenge}

The platform was created in response to the lack

of food security due to high population growth, climate change, shrinking cropping areas, an aging rural population, as well as a shortage of labour all puts a strain on future yields.

Through the platform,

improved common practices with new expertise can shared and implemented to tackle the challenge mentioned above.

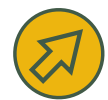

Intentions and Aspirations

The platform targets smallholder farmers and aims to contribute to the public good to improve of food and nutrition security as well as economic development in rural areas.

The vision of the platform is to contribute to enhance rice production and nutrition in SEA. This is done through better production via a sustainable increase production, standards and traceability. Moreover,

the vision encompasses better education through qualifications and trainings for stakeholders in the rice supply chain as well as promoting awareness for professionalisation and rice farming as commercially viable. Finally, the platform encompasses better nutrition, done via enhancement of the daily rice bowl fortification, advocacy and social marketing as well as increasing the nutrient value of crops.

The goal of the platform is to increase smallholder's income and promote rice-by products creating more job opportunities. The vision and goals of the platform is reached by adopting holistic value chain approach in order to achieve their long-term aims. from the private and public sector. The platform facilitates communication between members through publications and news \& activities pag on their website as well as training workshop documents also available online.
The platform is managed a BRIA secretariat, which overlooks four countryplatforms (Indonesia, the Philippines, Thailand and Vietnam) that is partnered along the rice value chain with PPP. The Secretariat, which is based in Bangkok (Thailand) serves as a regional hub and was set up in order to coordinate members, best practice exchange, establish regional networks as well as target knowledge transfers.

The specific role of the secretariat includes organising meetings and events, network building and maintenance, knowledge

and exchange management through collecting relevan data and information as well as enabling synergies amongst already existing projects/ institutions as well as to neighboring countries that may join in the future. The Secretariat is also in charge of public relations and communications as well as monitor and evaluation reporting. Finally it overlooks and explores options for new partners whether cofinancing sources in the region or project partners rrangements and Capacities

The platform provides core services for its members by improving local practices with new expertise. The core services include; capacity building and training activities in order for farmers to enhance their knowledge about Good Agricultural Practices (GAP), increasing yields and producing higher-quality rice. Moreover, the platform provides a Regional Knowledge Sharing Workshop on Best Rice Cultivation Practices.

Monitoring and Evaluation

No information available 


\section{(量) \\ General Information}

Initiated in 2011 Bonsucro is a certification body. It entails a global ( 38 countries) multistakeholder, non-profit organisation aiming to reduce environmental and social impacts of the production of sugarcane.

Members and Funds: Numerous members are involved in the Bonsucro platform including a range of international private sector members from the industrial sector, intermediate sector and end users. NGOs/ Civil Society involved range from an international scope and are from many types of backgrounds, moreover farmers are also involved in the platform (most farmers come from Brazil and India, and also include Mexico, Pakistan, Colombia, Fiji, Swaziland and Australia). is to infinitely maintain the sugarcane production value for the people, communities, business, economies and ecosystems in all areas where cane-growing is visible. stakeholders in the global sugarcane industry, who identified and discussed the key impacts (social and environmental) of sugarcane production. The platform was made in response to the lack of sustainability in current sugarcane production. In order to tackle this challenge, the platform is a focal point for the collaboration between members of the value chain as well as NGOs, to bring together different perspectives in order to create on the Bonsucro Standard.

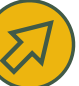

Intentions and Aspirations

The platform intends to develop sustainable producer communities for the sugar cane sector, and aims to target stakeholders who want to improve the productivity and sustainability via producing sugarcane, deriving products as well as buying and selling sugarcane products. The platform's vision echoes this as it wants to create a thriving, sustainable producer community with assured supply chains. Moreover, the mission

The platform has set three goals in order to achieve their vision/mission; (1) assured production, where the prochange and the certification for producers, (2) assured competitive space for buyer and traders to enable change and develop supply chains, and (3) assured origin, supporting the change priorities ing origins.

\section{The values of the plat-}

form encompass to inform by tools and advice, insights forum and output and pacts, to improve via programme support, increase assurance, and developing local programmes to address specific key issues and opportunities and, lastly to inspire the investment of resources, investing in change and identifying investment and technology areas to support local change. Moreover, these three values (inform, improve and inspire) are used in their standard as a strategy to buildgrammed and implementation of partnerships can accelerate supply chains, ensuring a prefor stakeholders in cane grow- ing a platform in order to accelerate change for sugarcane.

professionalism is aimed at those who are not convinced of a market-based value proposition- the programme focus is on attractive preferential investment or funding. Smallholder impact is progressed by leaning, validating and scaling programmes for smallholders. Being a part of the platform allows member to contribute to global awareness of CSR and global sustainability,

driving socio-political influence as well as access to global networks and shape the global model via technical/ scientific expertise member belongs to, members have to pay an annual fee determined by the Board.

Arrangements and Capacities

Amongst providing core services for the platform by organising trainings around the world, the platform also offers its members with

various core activities. The platform accelerates change by enabling members to be certified as quickly as possible, enabling scheme endorsements pinning them to a global framework and enabling platforms of learning and sharing. Moreover, productivity and communicated to the overall platform, (2) strategies of Bonsucro's standardsaiding the platform to gain a deeper understanding of the behaviour it is creating as well as its strengths/ weaknesses, and (3) organisational learning and adaptive management- to enable Bonsucro to gain better understanding on the effectiveness of the

organisation and strategies in house.

Bonsucro publishes an 'Outcome Report', which presents the finding of the platform's overall M\&E System. The main tool used to evaluate the sustainability performance and level of compliance with the platform's Standard for new members is 'The Bonsucro Calculator'. This is an excelbased system that processes production data from the mill and cane supple area/farms. 


\section{(9) Botswana Agriculture Hub}

$<$ Website

\section{弅 General Information}

Crop: No crop specified Geographic Scope:

Botswana

Initiated in 2008

The platform was created in order to position itself as the force for commercialization and diversification of

the agricultural sector in

Botswana.

Active Countries:

Botswana

Members:

Government (Botswana

Ministry of Agriculture)

\section{(日) Identified}

Lack of commercializa tion in the agricultural

sector in Botswan

The Hub has been created by the Botswana Ministry

of Agriculture, and is

implementing several

projects and initiatives to

commercialize the agricultural

sector due its high potential

for diversifying the economy

and creating employment,

especially in rural areas.

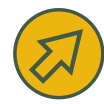

Intentions and Aspirations

Promote an economically

viable, sustainable

agricultural sector

though the production

of quality agricultural

products for local and

global markets

The platform, which is aimed mostly at traditional and

subsistence farmers, envisions

leading the transformation

of agriculture and thus

contributing to the wealth

of Botswana by 2020 .

BCI's mission is to be the

catalyzing force in agricultural

commercialization and

diversification. The platform

lives by the principles of: (1)

botho (treating customers

respectfully), (2) teamwork,

(3) being customer-focused,

(4) being innovative, and

(5) integrity. Additionally,

the platform aligns with

Botswana's National

Development Plan 10
Activities and Outputs

The board of the platform consists of the Minister

of Agriculture (14 people) and the Agricultural Hub

Coordinator.

\section{Arrangements} and Capacities

The platform provides

recommendations,

negotiations, and

interventions in order to

facilitate the implementation

of the projects and initiatives

it oversees. Moreover,

members receive a monthly

price bulletin that contains

the latest agricultural prices

of concern to the farming

community, as well as

Agrinews, which publicizes

information on the ministry's

development, projects,

policies, and programs, and

other relevant information.
Monitoring and Evaluation

No information available 


\section{(10) Business Alliance Against Chronic Hunger (BAACH)}

$<$ Website

\section{魚 \\ General Information}

Crop: Multiple staple and high-value crops

Geographic Scope: Africa

Initiated in 2006

BAACH is a locally-led and multisector National Council that explores approaches to building on the capacity and dynamics of business to create sustainable development and alleviate hunger and poverty. The platform is based in a pilot district, Siaya, which is considered the poorest district in Kenya.

Active Countries:

Kenya (Siaya)

\section{Members:}

Private sector (including multinationals such as Unilever, Tetra Pak, Mace Foods, and MAE Limited), government members (The Ministry of Kenya and the National Oil Corporation of Kenya, which is mostly owned by the government), international and regional agencies (such as Care International, CNFA-Agmark, and Technoserve), and expert members (including the SDG Center and Tegemeo Institute).
Identified Challenge

\section{Chronic hunger}

The platform was shaped by global CEOs and then the UN Secretary-General Kofi Annan. It aims to add value to tackling chronic hunger through business-led solutions, giving opportunities to those at the bottom of the pyramid. Moreover, the platform intends to engage with those in the public and private sector to provide both access to finance on a commercial model and technical support, while also building capacity and markets.

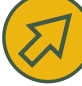

Intentions and Aspirations

To increase food production, nutrition, and income through strategies developed by private-sector expertise

The platform intends to improve value chains from production processing and packaging to retailing and marketing, in order to ultimately reduce hunger and poverty. The platform's vision is to share best practices from the Siaya district pilot project and to learn to replicate them across Africa. It aims to do so through multistakeholder partnerships, which focus on business expertise and market power to strengthen food value chains, as well as creating a more sustainable and equitable market system.

\section{(2) \\ Activities and Outputs}

The platform in Kenya is led by 20 members of the national council, consisting of local members of the global steering board, the Government of Kenya, and other local companies and stakeholders. It is run by a program manager.

\section{Arrangements} and Capacities

The platform offers a pilot voucher program for agricultural inputs such as maize and seed fertilizers

to 10,000 farmers. Through this, smallholders can

redeem discounted seeds and fertilizers at their local input dealers.
Monitoring and Evaluation

To information available 


\section{(11) Competitive African Rice Initiative (CARI)}

\section{A General Information}

General Information Crop: Rice

Geographic Scope: SubSaharan Africa

Initiated in 2013 (until 2017)

The Competitive African Rice Initiative was created to empower small-scale rice farmers in the Sub-Saharan region.

Active Countries:

Burkina Faso, Ghana, Nigeria, and Tanzania

Members:

International agencies (the German federal Ministry for Economic Cooperation and development (funding partners), Technoserve Kilimo Trust, The John A. Kufuor Foundation (implementing partners), the Bill and Melinda Gates Foundation, and the Walmart Foundation (funding partners).
Identified Challenge

Lack of adequate rice production

The platform was created through the collaboration of the Kilimo Trust (member of a pan-African consortium), led by GIZ and contracted by the Bill and Belinda Gates Foundation and the German Ministry of Cooperation (BMZ). The platform emphasizes cooperation with local companies, promoting their commitment through a fund to rice millers, whom must then match this with their own resources. This empowers smallholder farmers to be trained and business-oriented according to market demand. Moreover smallholder farmers obtain an advance payment from the rice millers in order to buy high-quality seeds, fertilizers, and agrochemicals.

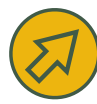

Intentions and Aspirations

Increase the

competitiveness of the

domestic rice supply

in order to improve

the livelihoods of rice

farmers

The platform aims to

reduce poverty among all

smallholders, rural service

providers, and rice millers.

Its mission is to use huma

capacity development to

increase business skills and

agricultural practices, and

to establish high-quality rice

production amongst small-

scale farmers. The platform's

vision is to achieve sustainable

success in the African rice

industry. In order to achieve

this, the platform's strategy

builds on identification,

optimization, and expansion

of sustainable business

models that integrate small-

scale rice producers.

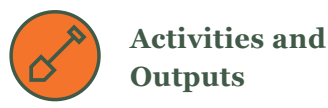

No information available
Arrangements and Capacities

A chairman of the supervisory board and management

board governs CARI. Each member is responsible for a country: (i) the Kilimo Trust is responsible for Tanzania, (ii) GIZ for Nigeria and Burkina Faso, (iii) Technoserve for Ghana, (iv) the John

A. Kufuor Foundation (in collaboration with Michigan State University) supports improved policy environment and alliance amongst stakeholders
Monitoring and Evaluation

No information available 


\section{周 General Information}

Crop: Cashew

Geographic Scope: Africa

Initiated in 2009

The Competitive Cashew

Initiative (ComCashew),

originally named the African

Cashew Initiative (ACI), intends

to establish a sustainable

cashew value chain and to

increase the competitiveness of

African cashew production and

processing. It is focused on five

countries in the African region.

Active Countries:

Benin, Burkina Faso,

Ivory Coast, Ghana, and

Mozambique

\section{Members:}

Private sector (Intersnack,

KraftHeinz, Olam

International, Red River

Foods, Walmart), government

(German federal Ministry

for Economic Cooperation

and Development, Ministry

of Food and Agriculture

of the Republic of Ghana,

Ministry of Agriculture and

Food security of Burkina

Faso), donors (German

Society for International

Cooperation (GIZ), African

Cashew Alliance, the Trade

and Development Group, the

Cotton and Cashew Board, the
Sustainable Trade Initiative, the United States Agency for International Development, and INCAJU), and civil society (Fair Match Support).

\section{Identified} Challenge

Lack of competition in the cashew sector and poverty

Launched using a

multistakeholder partnership approach, the platform

is mainly funded by the

Germany Ministry for

Economic Cooperation and

Development and the Bill and

Melinda Gates Foundation;

other members contribute to their specialty in the cashew

value chain.

The platform intends to facilitate information sharing between different actors on a national, regional, and international scope, within the public and private sector level. Known previously as the African Cashew Initiative, the platform has two stages; the first phase, which has now been completed (2009-2013) focused on the whole cashew value chain, while the second phase (2013-2015) combined all the training activities from phase one and is putting emphasis on creating linkages between farmers and processors, as well as better planting in order to increase cashew yield and quality.

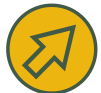

Intentions and Aspirations

To increase sustainability and competitiveness, create business

relationships between all stakeholders in the

value chain, create

homogenous goals

on the regional and

national levels, and to

use the support of donor

programs

The platform's vision is to increase the annual income, number of jobs, and the rate of processing of cashew nuts for small-holder individuals on the value chain-especially farmers and women, thus reducing poverty. The platform combats child labor in farming activities and ensures social responsibility through its partners. ComCashew operates in four areas to achieve its aims: (1) production, (2) processing, (3) supply-chain linkages, and (4) strengthening the organization of the cashew sector.

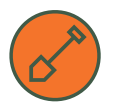

Activities and Outputs

The platform is governed by three teams in Germany, Ghana, and Burkina Faso and has commissioned GIZ (German International Cooperation) to manage the projects and to be the facilitator of cooperation amongst the private partners. rrangements and Capacities

The main activity provided by the platform is the $\mathrm{ACI}$

Cashew Matching Fund

(following a PPP model),

which is available for those in the cashew supply chain and to public research institutes, allowing them to explore beneficial implementation strategies. The platform has also enabled activities in its four key areas: (1) production where, in its first phase, the platform provided improved cashew planting material development and training programs on all aspects of the value chain in its second phase; (2) Processing where technical assistance was provided in the first phase, with linkages to financial institutions, whereas in the second phase, platform partners provided advice on areas such as technology management, food safety, and business services; (3) supply chain linkages, where farmer-based organizations (FBOs) were supported in creating organizational and management capacities; (4) cashew Sector organizations, creating business associations, stakeholder platforms, and extensions services in the first phase.
Monitoring and Evaluation

No information available 


\section{侖 General Information}

Crop: Cotton

Geographic Scope:

Sub-Saharan Africa

Initiated in 2005

An initiative of the Aid by

Trade Foundation (AbTF),

CmiA aims to empower people

through trade and improve

the social, economic, and

ecological living conditions of

cotton smallholder farmers

in Sub-Saharan Africa,

through the application of an

international standard.

Active Countries:

Benin, Burkina Faso,

Ethiopia, Ivory Coast,

Ghana, Cameroon, Malawi,

Mozambique, Tanzania,

Uganda, Zambia, and

Zimbabwe

Members:

Private sector (retailers,

fashion brands, textile

companies, spinning

millers, weaving millers,

ginning companies, traders,

exporters, service providers,

finance companies,

processors, manufacturers)

donors (Bill and Melinda

Gates Foundation, Social

Accountability International,

Welthungerhilfe, Deutsche

Gesellschaft für Internationale
Zusammenarbeit, World Wide Fund for Nature, the C7A Foundation, the Better Cotton Initiative), expert, technical, and research actors (WRAP, Plexus Cotton, Ethical

Expert, Alterra, Wageningen University, Bimeco

Garnhandel, Accenture, Accuracy, West Point Home Bahrain, Shandong Ruyi Technology Group)

\section{Identified}

The low living conditions of Sub-Saharan cotton farmers

The Aid by Trade Foundation is the umbrella organization of the CmiA, and acts

independently of the Otto Group. The platform provides ecological credentials to the international textile trade cotton, improving the livelihoods of smallholders and promoting the need for sustainable businesses.

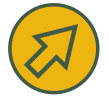

Intentions and Aspirations

To help people benefit from trade and to

preserve natural

resources in a sustainable manner

The platform's mission, aimed at Sub-Saharan smallholder farmers, intends to create transparency and support, and to offer a sustainable alternative to traditional textile production. The CmiA provides standards regarding the ecological, social, and economic aspects of cotton production and processing.

It does so via a teaching

approach, rather than donation-based approach. Smallholders learn about methods of sustainable and efficient farming. Moreover, the platform has created an international alliance of textile companies that buy CmiA raw material and pay a license fee to use the seal. This fee is then reinvested into the projects.

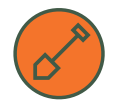

Activities and Outputs

The platform is governed by the trustees of the Aid by Trade Foundation, which has four key governance groups: (i) AbTF board of trustees (ii) AbTF management, (iii) verification management, and (iv) verifiers. Moreover, there are CmiA organic units, which are farmers who cultivate organic cotton, and managing entities (a secretariat) that finance the organic verification. The managing entities also decid who will be a CmiA farmer, who is responsible for criteria compliance, and who conducts annual self-assessments and submits them to the AbTF. rrangements and Capacities

The platform organizes activities, such as events with corporate clients and partners, to raise public awareness of the brand. The brand is also promoted via the Internet (YouTube videos, social networks, Facebook, and Twitter). Moreover, the website hosts many documents regarding the CmiA standard, textile chains, marketing and communication, annual reports, studies, and newsletters. The platform has also created the $\mathrm{CmiA}$ Community Cooperation Program, which backs projects in education, health, and environmental issues, as well as initiative for women. 
$<$ Website

\section{弇 General Information}

Crop: Maize, rice soya, rice, fruit, vegetables Geographic Scope:

Ghana

Initiated in 2012 (until 2019)

The GCAP aims to develop agriculture in Ghana in step with the nation's poverty reduction efforts and to increase food security through inclusive farming in selected commodity value chains. The platform consists of two projects; the Savannah Accelerated Development Authority (SADA) zone, focusing on the value chains of maize, rice, and soya, and the Accra Plains zone, focusing on maize, rice, fruits, and vegetables.

Active Countries: Ghana

\section{Members:}

Government (government and Ministry of Food and Agriculture of the Republic of Ghana), donors (The World Bank, The United States Agency for International Development), collaborating partners (The Ghana Investment Promotion Centre, the Ghana Irrigation
Development Authority, the Environmental Protection Agency, the Planning M\&\$ Directorate of MoFA, the Plant Protection and Regulatory services Directorate of MoFA, the Crop Services Directorate of MoFA, the Agricultural and Engineering Services Directorate of MoFA, and Woman in Agricultural Development)

\section{Identified}

\section{Poverty and food} insecurity

The platform, initiated by the Government of Ghana, aims to overcome the challenges by assisting farmers to remove constraints through matching grants. In 2014, the Government of Ghana and the World Bank agreed to restructure the Ghana Commercial Agriculture Project (GCAP), which consists of seven components, including securing PPPs, project management, and infrastructure support.

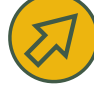

Intentions and Aspirations

To increase yield by $40 \%$, to increase gross margins by $40 \%$, to reach 14,000 direct beneficiaries (including $40 \%$ women), and to increase the area provided with improved irrigation by 10,000 hectares

The platform, which focuses mainly on poor households as well as on international

Ghanaian investors, intends to reduce poverty and increase food security through inclusive commercial farming in the commodity value chain. The objective of GCAP is to do so whilst providing increased access to reliable water, land, finance, agricultural inputs and output markets. In order to achieve this, the project

consists of three components:

(1) strengthening investment,

(2) securing PPPs and

smallholder linkages in the

Accra Plans, and (3) secure

PPPs and smallholder linkages in the SADA region.

\section{(2) Activities and Outputs}

There are 11 members on the GCAP steering committee.

The project implementation unit oversees the management of the project, with a project coordinator as the leader.

Moreover, the project involves collaboration with government departments and agencies. The representatives of these departments and agencies constitute the project technical committee.
The platform provides its members with a model lease agreement that acts as a guide for investors and land owners on large-scale land transactions, as well as assistance to the Ghana Investment Promotion Center and the Agribusiness Unit of MOFA, and matching grants for farmers. It also promoted a parliamentary statute to guide the operations of water users' associations. Training and workshops in environmental safeguards are also provided to members, as is assistance in preparing guarantees of environmental and social impact assessment (ESIA) and environmental management plans (EMP) and help in acquiring EPA permits. Finally, the platform provides a publication area where documents can be accessed, as well as an 'events' and 'new archives' section. develop an M\&E plan that will measure (1) impacts on the standard of living of affected individuals, households, and communities; (2) improvements in communities affected by the project; and (3) management of disputes and conflicts. Moreover, improvement of methods throughout the project are to be heightened through internal monitoring, while external evaluation focuses on whether policies have been complied with and proving lessons learnt for amending strategies and implementation. 


\section{(㝵) \\ General Information}

Crop: Maize

Country: Ghana

Initiated in 2008

The Ghana Grains Partnership (GGP) is a PPP, initiated in

2008, that aims to strengthen the Ghanaian grain market, allowing farmers to increase grain production and support the development of both a local and regional market. This involves the combination of smallholder development, the use of high-quality agricultural inputs, and the introduction of commercial bank lending to farmers. It invites bottom up dialogue with various stakeholders from private companies to farmer's associations regarding Maize in Ghana.

Members:

The platform was initiated by Yara (international

fertilizers company) and Wienco (Ghanaian inputs trader). Core members are The Ministry of Food and Agriculture, Yara, Wienco, Masara N'Arziki (a newly established farmer's organisation) and international NGOs.
Identified Challenge

\section{Low agricultura} productivity for

smallholder farmers

GCP aims to improve existing low agricultural productivity and profitability for smallholder farmers due to the lack of access to high quality and affordable inputs. The platform allows for collaboration between stakeholders, ensuring

improved efficiency

throughout the grain value chain, as well as conjoining commercial and developmen objectives at the nationa level.

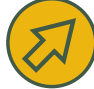

Intentions and Aspirations

Value chain approach to share costs, benefits and risks

GGP presents a holistic

approach and promotes open dialogue regarding farmer's

needs as well as the public and private sector that provides

financial benefits for the value

chain stakeholders. It works

to ensure smallholder farmers

$(8,000$ farmers as of 2013 ,

members of Masara N'Arziki)

have access to affordable

inputs and profitable output

markets through effective

institutional arrangements

(e.g. outgrower schemes)

training, extension and more

effective information flows.

The basic principles include

(i) sharing costs, benefits and

risks among partners;

(ii) building trust among

parties;

(iii) providing a learning

platform through openly

sharing information;

(iv) leaving the Partnership

open to new members

if similar risk sharing

methodologies are adopted.
Activities and Outputs

No information available and Capacities

The members of the platform contribute in various ways;

Yara brings knowledge via previous experiences with PPPs, as well as supplying fertilizer to the projects,

whereas Wienco provides the warehouse facilities. Both companies have financed the initial input requirements by establishing a revolving fund for input credits and logistics through two long-term loans totaling USD 3 million. Yara and Wienco have additionally trained a farmer's association called Masara N'Arziki, who would then sell inputs and train farmers, as well as buy their produce.
Monitoring and Evaluation

$\mathrm{M} \& \mathrm{E}$ is overlooked by an extension and zonal managers, ensuring that farmers are using new practices they have acquired. Technoserve (NGO) follows up on the training provided to farmers to ensure improved governance between farmer groups. 


\section{(16) Global Alliance for Improved Nutrition (GAIN)}

$<$ Website

\section{茼 General Information}

Crop: None

Geographic Scope: Global

Initiated in 2002

Launched at the United Nations, the Global Alliance

for Improve Nutrition is a global organization that envisions a world without malnutrition.

Active Countries:

Afghanistan, Bangladesh,

Brazil, Cambodia, China,

Ivory Coast, Dominican

Republic, Ecuador, Egypt,

Ethiopia, Ghana, Haiti, India,

Indonesia, Kazakhstan, Kenya,

Mali, Morocco, Mozambique,

Nigeria, Pakistan, Senegal,

South Africa, Tajikistan,

Tanzania, Uganda, Vietnam,

Yemen, Zambia

Members:

Government members (Canadian Department of Foreign Affairs, Trade and Development, Ministry of Foreign Affairs of The Netherlands) donors (international foundations such as the Bill and Melinda Gates Foundation and national and global development agencies), civil society (UNICEF), and others (Liverpool School of Tropical Medicine)
Identified Challenge

\section{Malnutrition}

Through innovative partnerships, the UN launched a platform aimed to act as a catalyst between governments, businesses, and civil society to deliver solutions to malnutrition.

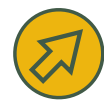

Intentions and Aspirations

To provide 1.3 million people with essential micronutrients by 2017

The platform, which focuses on women, children, an girls, envisions a world without malnutrition in order to break the cycle of malnutrition and poverty. GAIN works according to the values of: (1) teamwork (using the various skills of employees, as well as public and private partners), (2) innovation (testing innovative business models to ensure sustainability for vulnerable groups, (3) passion, and (4) professionalism. GAIN's

approach encompasses

a tailored approach to

innovation, scale and

ambition, and a strong focus on impact.

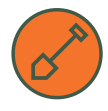

Activities and Outputs

The policy and decisionmaking body of the platform is the board, which is supported by GAIN's partnership council. The board consists of three standing committees:

(1) the finance and audit committee; (2) the board program committee; and (3) the nominations committee. GAIN's senior management team consists of an operations committee (responsible for the day-to-day management of the organization) and an executive management committee (which acts as a platform to discuss plans alongside GAIN's objectives, to seek agreements, and

to take ownership of the implementation).

\section{Arrangements} and Capacities

GAIN supports its countrylevel members to introduce and promote fortification approaches for different products (salt, cereals, etc.) with the aim of reducing undernutrition. 
$<$ Website

\section{(周) \\ General Information}

Crop: Coffee

Geographic Scope: Global

Initiated in 2006

The Global Coffee Platform is an inclusive multistakeholder platform using a diverse network of stakeholders to create a sustainable and prosperous coffee sector. It is a global platform; however, the countries differ according to group type: individual,

associate, trade and industry, producers, civil society, etc.

Active Countries:

Guatemala, Costa Rica,

Malawi, Rwanda, Laos, El

Salvador, Mexico, Italy,

Finland, Sweden, Austria, Isle of Man, Honduras, Nicaragua, Ethiopia, Burundi, Tanzania, Madagascar, South Africa,

China, Japan, Vietnam,

Malaysia, Indonesia, Papua New Guinea, Australia, New Zealand, Portugal, Spain,

France, Belgium, USA

Colombia, Brazil, Nigeria, Uganda, Kenya, Tanzania,

Zambia, South Africa,

Indonesia, India, Switzerland, UK, Germany, Netherlands, Guatemala, El Salvador, Peru, Ivory Coast
Members:

Private sector (trade importers and exporters, coffee roasters and retail industry, as well as banks), civil society members (rainforest conservation, fair trade, pesticides), development organizations, and farmer organizations.

\section{Identified} Challenge

Lack of sustainability (due to the threats of climate change, pests and disease outbreak, and aging trees and farmers)

The platform was founded by 37 members of the

Common Code for the Coffee Community (4C). Although the platform was founded in 2006, it was not until 2016 that it was publicly launched The platform intends to work together under a common vision and commitment, in order enhance resilience and the livelihoods of coffeefarming communities.

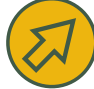

Intentions and Aspirations

To drive the collective impact of sustainable coffee communities by facilitating global and national agendas

The platform intends to provide a framework to measure and improve sustainability performance and sets a global baseline for sustainability in coffee production and processing The platform has three core functions: (i) to create a homogeneous platform that provides a common vision, acting on national priorities with governments and (ii) to aim for the adoption of a minimum requirement of sustainability for the whole sector, thus creating a level playing field for reporting and measuring improvements (the Baseline Common Code), and (iii) to provide the coffee sector with a Global Progress Framework, allowing efforts to be reported and measured.

\section{(1) \\ Activities and Outputs}

The GCP's board includes representatives of producers, traders, and civil society and is elected by the membership assembly. The secretariat, advisory boards, and committees oversee the operational functions of the platform. Communication is available throughout the platform in the form of annual reports, web portals and annual membership assemblies. rrangements and Capacities

The platform's main activities allow for collaboration

between members in regards to finance, identifying and coordinating technical assistance for small producers, accessing recent information, tools and sustainability practitioners, promoting gender and youth in sustainability approaches, and providing detailed guidance on pest management. It also offers a climate module. Moreover, the platform offers coffee assurance services (a global assurance service provider) for verifying the Baseline Common Code and measuring the integrity, assurance, and progress made in coffee.
Ongoing systematic monitoring of short and medium-term outcome indicators is completed to access the impact of the entrylevel standard on farmers and workers. The $4 \mathrm{C}$ Association published their first report in 2014 to provide an overview of the achievements and challenges faced in other key locations (Brazil, Colombia, Indonesia, Kenya, and Vietnam). 
$<$ Website

\section{(旬) \\ General Information}

Crop: Shea

Geographic Scope: Global

Initiated in 2011

The GSA promotes industry sustainability, quality

practices and standards, and demand for shea in food and cosmetics globally, through public-private partnerships.

Active Countries:

Afghanistan, Algeria, Angola,

Belgium, Benin, Burkina

Faso, Canada, Ivory Coast,

France, Ghana, Guinea, India,

Kenya, Libya, Luxembourg,

Mali, Netherlands, Nigeria,

Poland, Saudi Arabia, Senegal, South Africa, South Sudan,

Spain, Sweden, Switzerland,

Togo, Turkey, Uganda, United

Kingdom, United States

Members:

Private sector (collectors suppliers, brands,

retailers and supporters;

donors (foundations,

development agencies;

civil society (NGOs)),

farmers' organizations

(collectors, handcrafted

butter producers), and

others (consultants, research

centers)
Identified Challenge

Lack of decent work practices in the shea value chain

The platform, allows for collaboration between

businesses, multinationals, NGOs, and women to work together to secure the shea industry.
Intentions and Aspirations

To enable women's empowerment, decent

working conditions,

improved livelihoods,

and protection of

ecosystems

The PPP, which aims to improve the livelihoods of 53,319 African women and their communities, envisions being the foremost platform to satisfy strategic interests and the practical needs of its members. The mission is to design and deliver strategies that put forward a competitive and sustainable shea industry globally, coupled with improvements in livelihoods

of African women. The membership principles consist of growth promotion of the industry, best internationa business practices, dispute and complaint resolution, good corporate governance, improved quality, fair prices, communication, transparency, confidentiality, collaboration, and participation and payment of fees.

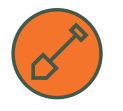

Activities and Outputs

The platform is governed by an executive committee, which is elected every two years by a general assembly. The advisory board consists of firms or individuals whose contribution exceeds $\$ 50,000$ in cash and support to the platform. The secretariat manages the day-to-day activities of the platform and reports to the executive committee. The secretariat

distributes general funds, as well as BUSAC project expenses, ICCO project expenses, USAID TIME expenses, and USA WATH expenses. rrangements and Capacities

The platform provides a baseline for shea kernel cost of production and farm gate prices, proper registration of women's groups with loca authorities, the facilitation of land donation to women's groups, the acquisition of construction services for warehouses, quality training, and provision of jute sacks and pallets to store shea kernels. The GSA organizes

several events for its members and has a 'Promotion' section on its website where all upcoming and past events can be accessed. Furthermore, there is a 'Shea in The News' tab, where information regarding GSA is collected and made easily accessible. There is additionally a 'Resources' section with access to a newsletter and the GSA library.
Monitoring and Evaluation

The sustainability working group oversees project results, challenges, and recommendations for improvement. The GSA also publishes a sustainability report each year consisting of M\&E information, as well as project-specific information on the data collected annually. 


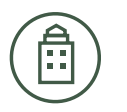

General Information

Crop: None

Geographic Scope: Africa

Initiated in 2011

A multistakeholder platform that aims to accelerate private sector investment in the African region.

Active Countries:

Benin, Burkina Faso, Ivory

Coast, Ethiopia, Ghana,

Kenya, Malawi, Mozambique,

Nigeria, Rwanda, Senegal, and Tanzania

\section{Members:}

Private sector (bank, seed suppliers, service providers, processors, exporters)

government (several

international development

departments), donors

(foundations, development

agencies, other platforms

such as AFAP, ACi, CARI, and EAGC), civil society (regional agricultural organizations).

\section{(日) Identified Challenge}

The potential of

agriculture is not

recognized

The Grow Africa Partnership, cofounded by the Africa Union (AU) and the World Economic Forum, is an African-owned, country-led, market-based, inclusive platform for crosssector collaboration. The platform enables collaboration between governments, international and domestic agriculture companies, and smallholders. It intends to lower the risk and cost associated with agricultural infrastructure, and improve return to all stakeholders.

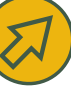

Intentions and Aspirations

To develop multistakeholder platforms,

incubate promising

business models,

promote innovative

solutions, and

accelerate the pace of

implementation and

return on investments

Grow Africa focuses on

farmers, women, youths, and smallholders that have been recognized for the potential of their input products or services, financial and data services, and training. The platform intends to reduce poverty and hunger through the Principles for Responsible Investment in Agriculture and Food Systems. The approach employed by the platform consists of driving investment commitments, working with international and domestic private sector investors, supporting improvements in the enabling environment, working with nationa governments, addressing systematic issues, identifying pan-African constraints to private sector investments, and sharing best practice.

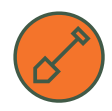

Activities and Outputs

The platform is led by a leadership council consisting of high-level representatives from member groups, who meet biannually. Grow Africa is facing a transition from being an autonomous entity hosted by the World Economic Forum to being hosted by the NEPAD Agency and governed by a multistakeholder steering committee. Grow Africa consists of a partner platform, network, and a secretariat. To become a member, a formal commitment to agriculture with the government in the corresponding country needs to be made. rrangements and Capacities

The platform offers its members an enabling environment for agribusiness, support in innovation and commercially competitive solutions, and an incentive to operate responsibly. Moreover, Grow Africa provides a Gap Analysis Tool for Agriculture (GATA), which is a web-based analysis tool that allows members to establish and prioritize potential agricultural projects. The website provides members with a resource section, including publications, videos, tools, updates, and a 'My Feed' section. When events are held,

the platform also provides summaries of discussions.
Monitoring and Evaluation

In order to establish the success of the investment commitments, the quantity of actual investment expenditure, the number of jobs created, and the number of smallholders with increased incomes are measured. 


\section{(亩) \\ General Information}

Created in 2015 Grow Asia is a platform that catalyzes action on inclusive and sustainable agricultural development in the South East Asian Region (ASEAN).

Members and Funds: Members involved in the platform include large

international multinationals, as well as members from the ASEAN group including the ASEAN Secretariat and ministry of Agriculture and Forestry. The World Economic Forum is also a member of the platform. Moreover, civil society/ NGO members include numerous members from conservation-based organisations as well as international NGOs. Farmer's associations are also involved in the platform and are planned to partner with the platform at the country level.

The overall funds that the platform has mobilized amounts to over $\$ 10$ billion in investment commitments. From this, $\$ 1.2$ billion has been spent, reaching over 3.6 million smallholders.
Identified Challenge

The platform was initiated by the World Economic Forum in partnership with the ASEAN Secretariat and other key public and private sector stakeholders, this was further developed during Grow Asia Agricultural Forum engaging over 140 leaders and various members.

The platform was created in response to the increase of population pressure in the area and thus, the increase demand of resources as well as pollution and degradation. Moreover, the rising issues in climate change all damaged agricultural production and farming communities. In order to address these challenges the platform serves as a focal point for numerous stakeholders to collaborate and work together to achieve change.
Intentions and Aspirations

The platform targets 471,200 smallholder farmers in order to contribute to food security, environmental sustainability and economic growth through sustainable agricultural development in South East Asia.

As the platform is a product of the World Economic Forum, and thus its 'New Vision for Agriculture', the platform's mission echoes this and aims to provide world needs regarding food security whilst doing so via sustainable agriculture. Grow Asia's vision is a $20 \%$

improvement in the area each decade until 2050. Moreover, the platform's goal is to reach 10 million smallholder farmers and facilitate them to increase their yield and profits by $20 \%$, using $20 \%$ less water and emitting 20\% less green house gasses per tonne of production, by 2020. rrangements and Capacities

The platform is governed by a multi-stakeholder Steering Committee, which oversees the Grow Asia Secretariat. The platform believes that its diverse multi-stakeholder representation s invaluable as it defined the platform's plans and different views whilst identifying priorities that help Grow Asia reach its targets. Key members of the platform is; the Grow Asia Business Council, Grow Asia Civil Society Council, Farmer Associations, ASEAN Secretariat, ASEAN Member States, donors and the World Economic Forum Managing Director.

The platform enables communication between members via an interactive platform that allows for discussion and shared learning amongst Grow Asia partners. Moreover, in order to achieve transparency and engagement Grow Asia posts summaries of decision made at every Steering Committee.
The platform provides its members with core activities in particular knowledge sharing which is done via online repository and learning hubs. This provides easy access for information across disciplines (including, case studies, policy papers, value chain analysis). The platform also connects Grow Asia partners to researchers in universities, think tanks, development practitioners and consultants via the Grow Asia's Learning Partner's Network in order to gain expert support.

The platform also provides members with core products including Scaling Solutions where Grow Asia collaborates with partners to pilot solutions. Moreover, the platform offers a Regional Finance Working Group that brainstorms and tests financial solutions that support smallholder farmers. Lastly, the platform aims to develop a mobile-based digital platform.

Core services the platform provides includes access to investment and training across South-East Asia to almost half a million smallholder farmers. 


\section{(21) Malawi Agricultural Partnership (MAP)}

$<$ Website

\section{周 General Information}

Crop: Multiple Crops (rice, cotton)

Geographic Scope: Malawi

Initiated in 2007

The Malawi Agricultural

Partnership (MAP) is a

value-chain-based project

aiming to build on the

success of Malawi's fertilizer

subsidy program initiated by

Prorustica and Yara.

Active Countries:

Malawi

Members:

The Norwegian government

and donors: the Alliance for a Green Revolution in Africa

(AGRA), the International

Fund for Agricultural

Development (IFAD), and

local authorities. Challenge

Ineffective subsidy programs and expensive

fertilizer supply chains

The Malawi Agricultura

Partnership (MAP) was

facilitated by Prorustica and

Yara, as well as other local

partners, in order to design

and facilitate a partnership

and related value-chain

projects. Their focus was

to create a more effective

subsidy program that is cost-

efficient and reduces costs

in the supply chain. This

platform is one of the key

programs implemented by the

African Institute of Corporate

Citizenship.

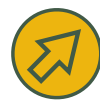

Intentions and Aspirations

To alleviate systematic problems and share risks

through a PPP that will provide commercial and developmental support

The platform, which is

targeted at smallholders, has three objectives: to create

an enabling environment,

to create an efficiency value

chain, and to create busines

services. It uses a collaborate

strategy working with

governments, private sector,

and donors to create an

investment plan that alleviates

problems in the fertilizer

supply chain.

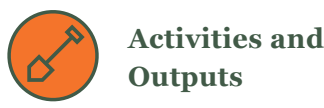

The platform is run by a board chair with three board directors.
Arrangements and Capacities

\section{The platform provides}

commercial and

developmental support to

sustainable and profitable

smallholders in Malawi.

Moreover, the Rice

Partnership coordinates

activities and supports the

awareness of a viable market

via a marketing model that

predicts the quantity, variety,

and type of rice that will be

bought by a particular buyer

in the partnership.
Monitoring and Evaluation

No information available 
$<$ Website

\section{(㝵) \\ General Information}

Crop: None

Geographic Scope: Africa

Initiated in 2012

The platform intends to achieve sustainable, inclusive agriculture-led growth in order to lift 50 million people out of poverty by 2022. The New Alliance for Food Security and Nutrition is a shared commitment by African governments, development partners and private sector companies in 13 African countries.

Active Countries:

Benin, Burkina Faso, Ivory Coast, Ethiopia, Ghana,

Malawi, Mozambique, Nigeria, Senegal, Tanzania

Members:

Private sector (about two thirds African companies involved in the production, processing, logistics, input, training, mechanization, storage, finance, and technology sectors, platforms such as the Global Shea

Platform and African Cashew Initiative), governments (Benin, Burkina Faso, Ivory Coast, Ethiopia, Ghana,

Malawi, Mozambique, Nigeria Senegal, and Tanzania),

donors (development agencies from Canada, France, Germany, Italy, Japan, Russia, the UK, the USA, and the EU; the African Development Bank, ILO, and the World Bank Group); civil society (Oxfam America), Farmer's Organizations (Eastern Africa Farmers Federation, Pan-African Farmers' Organization and ROPPA (Network of Farmers' and Agricultural Producers' Organizations of West Africa) and Southern African Confederation of Agricultural Unions), expert, technical, and research members (the African Union Commission, AGRA, the Association for Strengthening Agricultural Research in Eastern and Central Africa, the Centre for Coordination of Agricultural Research and Development for Southern Africa, the West and Central African Council for Agricultural Research and Development, CGIAR, COMESA, the Forum for Agricultural Research, Global Open Data for Agriculture and Nutrition partners, HarvestPlus, IFAD, IFPRI, SUN Movement, Semento Seed Consulting, University of California, Davis)

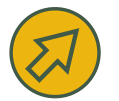

Intentions and Aspirations

Poverty and food insecurity

The potential of agriculture to reduce poverty and increase economic growth on the continent is very promising. Whilst agriculture and agribusiness currently represents nearly half of African GDP, growth in this presents a significant opportunity for investment. Building on Grow Africa's goals, the platform, initiated by the US government, engages additional

development partners, reflects commitments to cooperation frameworks, and addressing

broad issues through enabling actions.

components of CAADP,
To ensure donor

commitment, to

implement key

to provide private

investment in support

of development goals, to help 50 million people out of poverty in Africa by 2022 , and to achieve inclusive agricultural-led growth in Africa.

The platform, which targets private investments, contributes to the implementation of CAADP's goals to end hunger and halve poverty in Africa by 2025. Its mission and vision is to strengthen African agricultural productivity, sustainability, and inclusivity through public-private collaboration and marketbased strategies. The platform does this via stakeholder commitment to policy reforms and investments, partner accountability for commitments, enabling actions, and annual reporting.

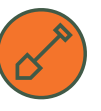

Activities and Outputs

The platform is governed by a Leadership Council coconvened by the African Union Commission, the World Economic Forum and the United States government. In a New Alliance country, the development partner is the lead interlocutor with the partner country on behalf of other development partnerships in implementing and monitoring the New Alliance.

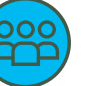

Activities and Output

The platform communicates via council meetings, annual reports, and summaries of letters of intent Evaluation

The M\&E approach of the platform is an individualistic one in which stakeholders report progress and challenges. The African governments in each country are responsible for overseeing and implementing the project as a whole. The general guidance of the platform states that countries need to hold an annual review of progress which is transparent, generates a mutually agreedupon country progress report, assess overall progress, and identifies key priorities for action. Moreover, countries need to report according to the CAADP results framework. 


\section{(旬) \\ General Information}

Crop: None

Geographic Scope: Global

Initiated in 2009

The New Vision for Agriculture is a project of the World

Economic Forum, which is

an international organization aiming to improve nations

through business, political,

academic and other means to shape agendas globally, regionally, and industrially.

Active Countries:

Benin, Burkina Faso, Ivory Coast, Ethiopia, Ghana,

Kenya, Malawi, Mozambique, Nigeria, Rwanda, Senegal,

Tanzania, Cambodia,

Indonesia, Myanmar,

Philippines, Vietnam, Mexico (with potential expansion to Brazil and Nicaragua)

\section{Members:}

Private sector (local and global traders, chemical producer companies, pharmaceutical companies, food processors, food companies, fertilizer

products, biotech companies, banks, crop protection companies), government (host governments), donors (International Finance Corporation, the Rockefeller Foundation), and others (consultants)
Identified Challenge

Lack of food security, environmental sustainability and economic opportunity

The platform was created with 17 global companies, and has catalyzed multistakeholder partnerships globally, including two regional partnerships: Grow Africa and Grow Asia. Its aim is to tackle the current challenges of the global food system, due to more volatile food prices, high levels of poverty and hunger amongst farming communities, and unsustainable practices that may cause environmental challenges in the future. In order to address this, the global partner companies have contributed leadership and technical expertise towards the full span of the food chain.

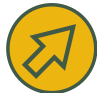

Intentions and Aspirations

Increase agricultural production by $20 \%$ each decade, reduce emissions per tonne of production by $20 \%$ each decade, and decrease the proportion of rural inhabitants living on less than $\$ 1.25$ by $20 \%$ each decade.

Focusing on farmers, the platform intends to eliminate hunger and

undernourishment. Its

vision and mission is for the agricultural sector to deliver food security, environmental sustainability, and economic opportunity in order to meet the world's needs through a market-based, multistakeholder approach. This is being done in three strategic ways: (1) facilitating leadership commitment,

(2) supporting country transformation, and (3) promoting innovation.

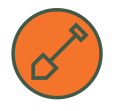

Activities and Outputs

The platform is governed by 26 global partner companies throughout the value chain. The NVfA forms part of the System Initiatives, and more specifically of 'Shaping the Future of Food Security and Agriculture' of the World Economic Forum. To ensure communication, the platform organizes several events yearly and provides a weekly newsletter on the global agenda.
Activities and Outputs

The platform provides its members opportunities for interaction through:

(1) leadership-level events (multistakeholder leadershiplevel events to build collaboration around shared goals), (2) multistakeholder country partnerships, and (3) knowledge and best practice exchange. 
(A) General
Information

PISAgro was established in 2011, to support Indonesian governments to address national food security through increasing agricultural production in a sustainable way, whilst improving livelihoods of smallholders. The platform focuses on the sustainable production of cocoa, coffee, corn, diary, horticulture, beef cattle, palm oil, potato, rice, rubber and soybean.

Members and Funds: The members of the platform include international multinationals especially in the food and agricultural products sector. Moreover, the Indonesian Government as well as the Department of Foreign Affairs and Trade in the Australian government are government representatives. International donors and agencies also partake in the platform including the World Economic Forum, International Finance

Corporation, Mercy Corps Indonesia, Monsanto and Swiss Contact. Lastly, civil society and NGO members include the Sustainable Trade Initiative, UTZ and Vasham. the Indonesian agricultural value chain. The platform's vision is to facilitate the necessary changes needed to enable the World Economic Forum's development of the New Vision for Agriculture in 2020. The Vision integrated food and nutrition security as well as environmental sustainability and economic opportunity improving each by $20 \%$ per decade until 2050. Moreover, the objective is to achieve a $20 \%$ increase in agricultural productivity, farmer's income and a $20 \%$ decrease in greenhouse gas emission each decade.

The platform functions via their basic principles of; (1) modular- where the involvement of modules are used as the basic replication to scale-up the project, (2) Across the Value Chain- Share seeds to farms inclusively to farm, from farm to shop shelves, (3) Inclusivebeing open to any party and institution to be involved in the activities of the supply chain and involving farmers into the chain to ensure sustainable livelihoods, (4) Scalable- create and share proof of concept. The platform also obtains governance principles where each member of the governance bodies has to demonstrate in their behaviour including; (1) Accountability, (2) Value adding, (3) Active, (4) Commitment, achieve its vision/ mission the The platform aims to ensure global food security and environmental sustainability via a market-based approach and targets those stakeholders in and, (5) Non-Dominance. In order for the platform to platform has established working groups around Indonesia's 10 priority commodities, where they develop the value chain and tailor a work plan and requirements, targets and timelines according to the commodity. Moreover, each value chain requires a launch pilot activities that range from management training to access to finance/ market. Lastly, there is a working group on agri-finance to implement financial tools and risk sharing approaches across the value chain. ment and other nominees. They ensure there is a proper linkage with key decision makers in the correct ministries, proper resource allocation for PISAgro's related activities, and assure there is a link between the senior government official and PISAgro leaders. The Board consists of members of the founders committee and three Board members that are elected via a criterion where there are terms and elections. The Board's role consists of operational oversight of PISAgro, provides guidance to Working Groups regarding the basic principles of PISAgro and assure full authority and responsibility remains within the Working Groups as well as obtain the power to ask a board member to step down at anytime if they do not comply to their duties.

Moreover, the Working Groups consists of a ing Committee where they have full accountability for achieve the platform's objective and adherence to PISAgro's principles for the crop that it is working on (one working group per crop). It assures quarterly reports on progress to the platform's secretariat as well as summerises key actions national and local government should take (provided at least once a year). The role of the secretariat is to empower and support the board in its key roles and being the linking-pin to key internal and external stakeholders. More over the secretariat enables information sharing of best practice and assures transparency, as well as attracting new members and serves as one door access for government entities to PISAgro.

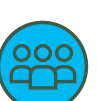

Arrangements and Capacities

The platform provides core activities including the facilitation of collaboration amongst stakeholders in the Indonesian agricultural sector. It allows for the facilitation of dialogue exchange, mobilization commitments and new partnerships that utilises the strengths of each stakeholder. Moreover, the platform holds General meetings, however unclear how regularly. Che Chairmar ensure the Board works via the principles of PISAgro as well as being staffed with functionin chairmen and members, mix of sectors and that it remains apolitical. They board meets once a year minimum.

The advisors of the platform are members of the govern- 


\section{(25) Patient Procurement Platform}

\section{骨) \\ General Information}

Crop: Maize

and other crops

Geographic scope: Global

Initiated in 2015

The Patient Procurement

Platform (PPP) was initiated

by the United Nations' World Food Programme (WFP), in partnership with Grow Africa and Rabobank. It aims to

create efficient value chains to enhance farmer's income. It

aspires to reach 25 countries globally, but currently

operates in Rwanda, Tanzania

and Zambia where the focus

crop differs for each nation.

Active Countries:

Rwanda, Tanzania, Zambia

Members:

International fertilizer and

agribusiness companies

(Bayer, Syngenta, Yara

International), international

organizations (AGRA,

The International Finance

Corporation, Rabobank,

GrowAfrica), international

donors (WFP as the main

one) and local members of the value chain.
Identified Challenge

Increased food security and lack of access to

markets

The platform aims to tackle lack of food security for family

farmers, as well as the lack

of access to reliable markets.

Through the PPP there is

an assurance of markets for

farmers from the WFP which

ensures that the WFP sources

its food from local farmers,

contributing to the Global

Goal of zero hunger.

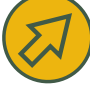

Intentions and Aspirations

Ensure access to markets for smallholders

The PPP intends to ensure access for small-holder farmers to reliable markets,

linking them with an effective

value chain, and establishing

a stable demand-driven

purchase system, hence

increasing the farmer's

income. The platform builds

on WFP's previous work

through Purchase for Progress

(P4P) that supports small-

scale farmers to be included

within the existing value

chain. ctivities and Outputs

No information available
Arrangements and Capacities

The platform offers farmers access to quality seeds

and other inputs, and also insurance and financing as well as a predictable market. It helps farmers set contracts with buyers for their crops before planting.

This assurance of a market for their produce can then help farmers to obtain bank loans or other financial services

which they can then use to buy better seeds, fertilizer and other agricultural inputs in order to plant more and sell more after harvest. This encourages farmers to become more resilient through greater advance planning and assured sales.
Monitoring and Evaluation

No information available 


\section{(㝵) \\ General Information}

Crop: Not crop spefici Geographic scope: Global

Initiated in 2007

Prolinnova-Kenya (PK) is a network of non-governmenta organisations (NGOs) government research and extension organisations, farmer organisations,

universities and communitybased organisations (CBOs) It came together in to foster learning about promoting farmer-led innovation processes in 2007. It was initiated by 25 partners in agricultural R\&D in a meeting organized and facilitated by the coordinating NGO of Prolinnova-Uganda.

Active Countries:

Kenya

\section{Members:}

None specified. In general, it is comprised of networks engaging government research and extension organisations as well as NGOs, Community Based Organisation (CBSs), farmer organisations and universities. There is an International Steering Committee formed by the Royal Tropical Institute (KIT) the International Institute of
Rural Reconstruction (IIRR), Institute of Natural Resource (INR) and the Promoting

Farmer Innovation and

Experimentation in the Sahel (PROFEIS)

\section{Identified Challenge}

\section{Lack of farmers'}

resilience to external

shocks

The aim is to address is the lack of farmers' resilience

towards of their livelihoods changing conditions. It seeks to recognise the dynamics of indigenous knowledge and

to enhance the capacities of farmers to adjust to change by developing their own

innovations and appropriate systems of natural resource management (NRM) so as to achieve food security sustain their livelihoods and safeguard the environment.. Aspirations

Learn from local knowledge and enhance farmer's resilience through their own innovations and systems

The platform brings together multiple stakeholders, and targets networks of farmers, pastoralists, researchers, development agents and policy makers to promote information exchange regarding sustainable local innovations. Through this, the platform intends to enhance food security, safeguard the environment, and improve rural and urban livelihoods, in order to offer sustainable livelihoods via local

innovations regarding local and natural resources. Their mission is to fostered foster a culture of mutual learning through networks and capacity strengthening in local innovation processes, as well as up-scaling in agriculture and NRM.

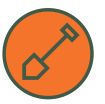

Activities and Outputs

The information below relates to the global

Prolinnova platform

The platform often operates through a local NGO at the country level, as the focal point. The NGO convenes major stakeholders, serving as the secretariat for the

National Steering Committe (NSC), involving researchers, extension and education and other NGOs, farmer groups and occasionally the private sector. The secretariat also determines the tasks

in order for individua

membership to become part of the International Support Team (IST) and the partner organisation where the NGO has to allocate their staff members holding a MoU. The role of the NSC is to give strategic guidance and mobilise resources, and it is the focal point for accountability. The NSC has a small team that coordinates day-to-day activities. In addition, the IST supports the national activities via capacity strengthening, coordination, coaching, policy dialogue, networking and communication and Capacities

The platform delivers cor activities to its members including; developing an inventory and database of existing local innovations innovators and partner organisations in Kenya, building the capacity of stakeholders in participatory approaches for agricultural $\mathrm{R} \& \mathrm{D}$, developing a strategy in order to increase awareness amongst all stakeholders on

local innovation, ensure join innovation by strengthening partnerships between stakeholders, setting up a multi-stakeholder platform for knowledge sharing on strengths and weaknesses of promoting local innovation and local initiatives in Kenya, and developing a M\&E framework. Moreover, information is available via videos, leaflets, report and other communication materials on their website.
Monitoring and Evaluation

An M\&E framework with guidelines for the global and local PROLINNOVA tracking of results was developed in 2006. An international workshop to learn from the M\&E experiences was held in Ethiopia in 2010. With support from CIRAD (France),

the country platform

(eg. Kenya) developed a participatory impact assessment guideline in 2010. 


\section{(周) \\ General Information}

Crop: Not crop specific Geographic scope: Global

Initiated in 2002

ProRustica fosters growth in agricultural commodity markets for the benefit of all those involved through the use of partnerships. It is a global platform with a focus on Tanzania, Malawi, Ghana and Mozambique.

Active Countries:

Tanzania, Malawi, Ghana, Mozambique

Members:

international agribusiness companies, banks and

consultancies (Yara

International, Shorebank

International, $\mathrm{SAB}$

Miller, Wienco Ghana,

PriceWaterhouseCoopers),

international donors

(International Fund for

Agricultural Dvelopment

(IFAD), NORAD, Acacia Social

Development Foundation,

The World Bank, European

Bank for Reconstruction

and Development (EBRD),

NORFUND, Africa Enterprise

Challenge Fund, Bill and

Melinda Gates Foundation,

Deutsche Investitions- und

Entwicklungsgesellschaft mbH

$<$ Overview all MSP's
(DEG), Facility for Farmers

Access to Markets (FFAM),

Mountain Area Development

Agency, United Nations Office

for Project Services, Food

and Agriculture Organisation

(Investment Center), as well

as local institutions and

governments.
Identified Challenge

Catalyst for partnership development

The platform was made in response to the lack of efficiency between private and public actors as well as few

large-scale farmers involving smallholders and their lack of access to commercial finance

to existing and emergent

farmers. The platform acts

as a catalyst for partnership

development that aids

emergent farmers become

commercially focused and

innovative in value chains.

\section{(2)}

Intentions and Aspirations

\section{Establish value chains}

ProRustica's role is to establish partnerships among specific value chains, and thus strengthening and developing comprehensive and innovative strategies to allow market access for rural populations.

The platform develops partnerships through a holistic approach to the supply chain and commodities, as well as an external analysis that observes the key players and actors involved, followed by an analysis of constraints and developing a plan that is suitable for all stakeholders.

ctivities and Outputs

No information available and Capacities

ProRustica provides its clients a neutral platform to design and implement joint plans, as well as access to financial facilities and skilled personnel, a comprehensive analysis regarding commodity markets, development of communication/ information exchange, solutions for obstacles as well as building local institutional capacities.
Monitoring and Evaluation

No information available 


\section{(旬) \\ General Information}

Crop: Cash crops (soybean, maize and sugar cane)

Geographic scope:

Mozambique

Initiated in 2009

ProSAVANA was created in 2009 with a 20-year horizon, focusing on agricultural development of the tropical Savannah (Nacala Corridor in Mozambique), through triangular co-operation. The focus of the platform mainly includes cash crops such as soybean, maize and sugarcane. It was created by a joint initiative between MASA JICA and ABS; inspired by the experience of the Brazilian Agriculture and Livestock Development programs in partnership with JICA

Active Countries: Nacala Corridor

(Mozambique)

Members:

the Ministry of Agriculture

and Food Security of

Mozambique (MASA),

The Japan International

Cooperation Agency (JICA)

and The Brazilian Cooperation

Agency (ABC).
Identified Challenge

Low agricultural productivity and high vulnerability to climate shocks

The platform aims to tackle low agricultural productivity and high vulnerability to weather shocks, which results in cfood insecurity and instability for populations. It aims to overcome the bottle neck of small markets via export zones through largescale farming.
Intentions and Aspirations

Improve the livelihoods of the Nacala Corridor population, through inclusive and sustainable agricultural and regional development

To improve the livelihoods of the Nacala Corridor population, through inclusive and sustainable agricultural and regional development. Its mission is to improve and modernise agriculture to increase productivity and production, and diversify agricultural production and to create employment through agricultural investment and establishment of a supply

chain. ProSAVANA's goal is to new agricultural development models, taking into account the natural environment and socio-economic aspects, and seeking market-orientated agricultural/rural/regional development with a competitive edge. ctivities and Outputs

In order for the platform to operate, projects under the ProSAVANA framework are co-coordinated jointly by MASA, JICA and ABC.

There is an administrative coordination unit named ProSAVANA-HQ (based in Maputo), created by the three members named above, to increase effectiveness of the platform's operations.

HQ's tasks include

communication, coordination and implementation of the platforms projects, linking the Programme with the directorate of MASA and promoting dialogue with stakeholders related to the programme. It is also the point of contact for the private sector, civil society and academics willing to participate in the platform. rrangements and Capacities

The platform provides both internal and external communication materials (i.e. leaflets and posters) for its members. It also supports members' access to markets and the creation of new value chains when required, as well as improved access to agricultural inputs and their distribution.

The platform also supports agricultural extension services by the private sector, access to agriculture credit, as well as encourages collaboration between

farmers and agribusiness. Finally, ProSAVANA has supported the development of agricultural infrastructure such as logistics and irrigation systems.

1 This section proves unclear whether it forms part of the separate projects of ProSAVANA or for the members of the platform.
Monitoring and Evaluation

No information available 


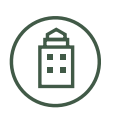

General Information

Crop: Soy Geographic scope: Global

Initiated in 2006 The Round Table on Responsible Soy is a civil organization that promotes responsible production, processing and trading of soy on a global level.

Active Countries: Global

Members:

The platform consist of an international range of private sectors and many large international supermarkets and multinationals, categorised as 'industry, trade \& finance', government members are also associated with the platform, especially from South America (Brazil and Argentina), as well as the United Kingdom, Belgium, USA and Canada. Civil society from the development sector, environmental conservation, solidarity and known international agencies such as the WWF. Expert/ Technical and Research members include private companies, labs and educational institutes from a range of countries in South America, Europe, USA and Canada.

\section{Identified Challenge}

Negative social and environmental impacts from soy production

The Round Table for Responsible Soy was made to respond to the negative impacts on social and environmental issues derived from the production of soy. The platform allows for an exchange of harmonious dialogue and decision-making between members. In 2004 the Responsible Soy Forum was initiated in London, however, the development of the RTRS took place in Switzerland, where major organisations including Grupo Maggi, Cordad, COOP, WWF, Fetrauf-Sul and Unileve took part as the original Organisational Committee. In 2010 the first version of the RTRS standard was launched.

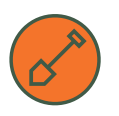

Activities and Outputs

Sustainable production of soy across the value chain

The platform focuses on the sustainable agriculture of soy and all those involved in the soy value chain from producers to sellers. The main objective/ goal of the platform is to facilitate a dialogue on a global scale, as well as; having a common consensus between stakeholders, be a focal forum for global soy production and promote the round table process in other sectors. In order to do so, the platform obtains pillars in which all must comply; legal compliance and good business practices, responsible labour conditions, responsible community relations, environmental responsibility and perform good agricultural practices. fairly represents all the
The governance framework constituencies involved and interested in the soy value chain: Production; Industry, Trade \& Finance; and Civil Society. The General Assembly is the highest decision-making body of the platform. made of 15 members (voted by RTRS member), from 3 chambers (Environmental and Social NGOs, Industry and Trade, Producers. Each member category has a maximum of 5 representatives with the same voting rights. The organisation's management, communications and technical tasks are managed by an

Executive Secretariat based in Buenos Aires, Argentina, and runs as an operational center for offering services to its members. There is a membership fee for the members, however this depends according to the category of membership.
Arrangements and Capacities

The platform delivers core activities to its members by placing the platform on a global level and making it applicable to the production of soy for different purposes, as well as producers of all sizes. It is valid for all types of production and links to the SDGs of sustainability communities. Moreover, the platform provides core products including RTRS Credit and a RTRS Credit Trading Platform. One ton of certified soy is equivalent to one credit of responsible soy production. This can then be used in the RTRS Credi Training Platform in order for businesses or organisations to make claims to show its commitment to the platform. Moreover, this can also be directly visible to customers and consumers buy RTRS products. (v) Monitoring and Evaluation

The RTRS certifications assures that soy, whether a raw material or as a byproduct originates from an environmentally, socially and economically viable manner. The traceability is kept via two models of supply chain (i) segregation, where soy that is RTRS Certified is physically separate from other nonRTRS Certified soy; and (ii) mass balance, where soy from RTRS- Certified properties may be mixed with sources of Non-Certified Soy, where the mixing process is monitored from the management. Once the mixing process is finalised equivalent percentages of certified and non-certified soy may be sold at the market place. 
$<$ Website

\section{(周) \\ General Information}

Crop: Palm Oil

Geographic scope: Global

Initiated in 2004

Not-for-profit organization that unites stakeholders

from the 7 sectors of the

palm oil industry: oil palm producers, processors or traders, consumer goods manufacturers, retailers, banks/investors, and environmental and social nongovernmental organisations (NGOs), to develop and implement global standards for sustainable palm oil. It started in 2001 by the WWF (World Wide Fund for Nature), resulting in an informal co-operation amongst Aarhus United UK LTD, Migros, Malaysian Palm Oil Association and Unilever in 2002. In 2004 the RSPO was formally established and 47 organizations signed a Statement of Intent to their commitment to the RSPO.

Active Countries:

Global

Members:

Private sector including international buyers (large bakeries), international palm oil producers, international palm oil processors and traders and international retailers such as multinationals and big supermarket chains. NGOs, from international environmental and conservation areas as well as social and development NGOs. International banks and investors.

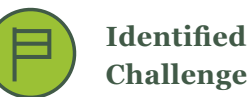

Deforestation due to unsustainable practices on the production of palm oil

The RSPO was set up to address deforestation due to the unsustainable practices of palm oil, land grabs where local communities are displaced from their land, and violations of worker's rights. As a response to these issues, the platform desires to transform the palm oil industry in collaboration with the global supply chain.

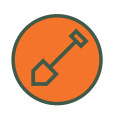

Activities and Outputs

Sustainable palm oil production

The platform engages in sustainable palm oil production as well as

improving the working conditions of employees in the palm oil value chain.

The platform envisions a norm within markets of sustainable palm oil, with the goal to promote growth and use of sustainable oil palm products via credible global standards and engagement of stakeholders. The mission echoes this as it encompasses the promotion of sustainable palm oil products, periodically review credible global

standards for the supply chain of palm oil, monitor and evaluate the economic, environmental and social impacts of sustainable palm oil in the market as well as ensure all the platform members are engaged.
RSPO is managed by the Board of Governors, where members are designated by the General Assembly for a 2-year period. The Board of Governors is supported by 4 Standing Committees that oversee; Standards \& Certification, Trade \& Traceability, Communications \& Claims and Finance. Each sector has a differing number of seats on the board. The RSPO Working Groups and Task Force Groups encourage members to address complex challenges and provide solutions. The Secretariat is based in Kuala Lumpur (Malaysia) and is in charge of day-to-day activities.
Arrangements and Capacities

RSPO issues a sustainable certificate to all members that comply with the standard, access to a strategic platform to influence policies, a dispute settlement facility, and support to ensure best agricultural, environmental and social practices.
Monitoring and Evaluation

Annual Communicatio of Progress reports are submitted to the RSPO members in order to observe their progress. 


\section{旦 General Information}

Initiated in 2009 The Scaling Up Nutrition (SUN) platform created a movement on the principle that everyone has a right to food and good nutrition in global context. The platform collectively brings together people from governments, civil society, the United Nations (UN), donors, businesse and researchers in order to improve nutrition. So far, the platform intends to reach 55 countries globally.

Members and Funds: The members of the SUN Network entail a (1) Civil Society Network, (2) Donor Network, (3) Business Network, (4) UN Network for SUN. Each country has a different profile of members at the local level, which can be viewed on the link. On the global level, the business network seems to have a coherent theme of multi national companies in the food retail sector as wel as the agri-chemical sector, whereas donors are international organisations such as the Bill \& Melinda Gates Foundation as well as organisations from more developed countries. The government of 50 countries have committed to help improve the nutrition of their country. The website presents viewers with a interactive map of each country and colour codes the different type of members involved

dentified Challenge

The platform was made in response to the growing global problem of under nutrition, where concern was high on the international system failing to deal with the problem effectively. This issue was further highlighted in the Lancet 2008 series on maternal and child nutrition, where the need to tackle child stunting was emphasised. Th platform aims to tackle the SGD of ending world hunger by collaborating members to support under nutrition from the country level, and with multi-sectoral strategies.

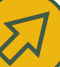

Intentions and Aspirations

The platform intends to address the underlining causes of malnutrition to those who suffer, and aims to meet the global targets established at the 2012 World Health Assembly. The SUN Movement engages in principles of; transparency about intentions and impacts, inclusiveness, being rights based, willingness to negotiate, mutual accountability, cost-effectiveness, enabling communication, acting with integrity and a high ethical manner, being mutually respectful and will not harm.

In order to tackle malnutrition each country goes through 3 stages; (1) Taking stock and starting out (creating plans and strategies as well as establishing institutional arrangements and engaging members). (2) Ready for scaling up (Developing an established functioning multi-stakeholder platform, including a budget plan, prioritising actions and outcomes and creating timelines). (3) Scaling up rapidly to deliver results (Operating programmes and interventions at scale, supported by executive-level political leadership, tracking progress, mobilising financial resources).

The platform engages in four strategic processes enabling bringing people together, establishing current policy and legal framework, aligning policies around a common results framework and financial tracking and resource mobilisation. platform support organisations. Moreover, the SUN Movement Secretariat ensures that progress is tracked and efficient as well as being communicated clearly. The secretariat works under the guidance of the Lead Group. The Secretariat employs lessons, sharing experience and evidence building of country experiences through self-assessment exercises. Communication of the SUN in practice is a series of briefs as well as sharing of Community Practices including a series of workshops. aligns resources and collaboration for improved nutrition.

The SUN movement lead group was designed to provide strategic guidance and improve the resource mobilization and accountability. The SUN Executive Committee acts on behalf of the SUN Movement Lead Group to develop and implement the platform's strategy and to support the SUN Movement Coordinator in ensuring political commitment and promote the values of the platform. The SUN Movement Coordinator works alongside the SUN Lead Group, SUN Networks and SUN Movement Secretariat to provide strategic leadership.

The SUN Movement MultiPartner Trust Fund was designed to catalyze grants, reaching governments, UN agencies, Civil society groups and other
Arrangements and Capacities

The platform provides core activities by seeking support to SUN Countries by strengthening their capacity to delive results, and improved nutrition.

Core services include join events such as Annual Global Gatherings as well as an exchange of knowledge and shared experienced and building on evidence base experiences. The SUN Country Network also benefits from overall support and coordination by the SUN key groups ( SUN Movement Coordinator, SUN Movement Secretariat, SUN Multi-Partner Trust Fund). itoring and Evaluation

In order to develop a practical approach to M\&E and the effectiveness of the SUN Movement, the SUN Secretariat worked alongside MDF Training and Consultancy to develop an M\&E framework. It is based around assessing the institutional transformation and actions towards scaling up nutrition across four processes to achieve the four strategic objectives outline in the SUN Movement Strategy and provides a clear way to evaluate progress in each process of the four processes.

The method to M\&E is via an Outcome Mapping methodology, which looks at how the behaviour of actors at the country level is changing within the four processes. Monitoring is undertaken bi-monthly via the SUN Country Network and an annual self-assessment taken by the countries. The SUN Movement Self-Assessment Exercise allows for different monitoring requirements and cycles of key stakeholders. Moreover, it ensures that consistency in demonstrating progress at the same time and enables the platform to identify progress behaviour across the movement. 


\section{用 General Information}

Initiated in 2010 SAGCOT, a multi-stakeholder partnership, was created to rapidly develop Tanzania's agricultural potential, stretching from the East (Dar es Salaam), to the West Zambia border. The platform has a focus on developing the agricultural production of grains/pulses, rice, sugar, citrus, banana, horticulture and the development of livestock and diary.

Members and Funds: Members of the platform entail the private sector, including a range of members from international multinationals from the food consumer goods section and agriculture related companies. Government members form Tanzania are also involved in the partnership, more specifically the Agricultural Seed Agency (ASA), the Financial Sector Deepening Trust (FSDT), the Tanzania Investment Bank (TIB), The Tanzania Investment Centre (TIC), and the Rufiji Basin Development Authority (RUBADA). Moreover, international donors and agencies form part of the platform (large international donors/ agencies many deriving from nature conserve sector). Tanzanian Farmer organisations also partake in the SAGCOT platform.

The platform Investor Blueprint has private investment catalyst of $\$ 2.1$ billon for over a 20-year period, as well as public sector grants/loans of $\$ 1.3$ billion.

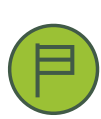

Identified Challenge

The platform tackles the issue regarding lack of food security, agricultural productivity and lack of livelihoods. With the correct investment and infrastructure, the platform believes that Tanzania has the potential to strive. The platform brings together multiple stakeholders in order to create a comprehensive and inclusive initiative.

The platform was initiated at the WEF Africa Summit, and the platform Investment Blueprint was launched nationally by the Prime Minister Pinda, and internationally by President Kikwete at the WEF in 2011.
The platform intends to improve food security, reduce rural poverty and ensure environmental sustainability as well as promoting responsible investments. SAGCOT targets agribusiness partners in order to develop the agricultural sector, consumers in East Africa to tackle the issue of food security, and the poor that depend on agriculture for primary income to address poverty reduction.

The platform vision is to triple to area's agricultural output by approximately 350,000 hectares to bring in profitable production to smallholder

farmers and areas of significant under irrigation. The platform's goals/objectives by 2030 is to; enable smallholders to become commercial farmers that can access irrigation and weather insurance, empower 420,000 new opportunities in the value chain, allow more than two million people to be lifted out of poverty, increase the annual value of farming revenues to $\$ 1.2$ billion, assuring regional food security in the region, fostering inclusiveness and a commercially successful agribusiness for small-holder farmers to benefit, and finally, to deliver sustainable agricultural growth that is socially and economically viable.

The platform functions via the SAGCOT board that consists of 7 members from government, research, business and consultancy. The platform falls under the national Kilimo Kwanza GrowthTrust, where funding is only made available to those investors who commit to building sustainable and equitable partnerships with smallholder producers. The administrative unit that serves as a hub to promote investment inclusive, sustainable commercial value chains is the SAGCOT Center Ltd, which also serves as a neutral broker and catalyst linking stake-

holders to create synergies and provide steps further to achieve the overall objectives of the platform.

The requirements to become part of the SAGCOT partner- ship is the notion of the common culture, which extends to an agreed code of conduct and principles for all partners. These include the agreement of; the overall SAGCOT objectives, to work with other members in a harmonious manner, engaging with the partnership and maintaining communication and support to the SAGCOT Center, resolving any policy and infrastructure constraints, and to consider new financing mechanisms.

facilitation of communication between stakeholder, improv ing coordination between government and donor programmes as well as helping to mobile funds. Furthermore, commissioning targeted applied research and making information on investment and support opportunities visible as well as monitoring the social and economic impact and knowledge sharing. Moreover, SAGCOT partners have access to information, networking and professional services including the Partnership Forum where knowledge exchange on best practices is seen.

SAGCOT, as well as providing its members core products including annual progress reports, convening of partners and impact reports, the platform offers core activities that incentivises strong linkages between smallholders and commercial agribusiness. Moreover, the platform offers support to smallholder producer associations in order to help them enter equitable commercial relationships with agri-processing and marketing business. Additionally, the platform presents core services for its members giving the sense of a very collaborative platform. These include, monitoring progress and annual performance reviews, the 


\section{侖 General Information}

Since 2011

The Sustainable Rice Platform (SRP) promotes resource

efficiency and sustainability on farm, and throughout the rice value chain, in global rice growing areas.

Members and Funds: The platform invites a multistakeholder environment, where private sector members including international MNEs especially consumer goods for food and the agricultural sector, the Ministry of Agriculture and Rural Development, and Crop Production for Vietnam and the Thai Rice Department and Ministry of Agriculture and Cooperatives are members. Additionally, other members include international donors and agencies (i.e. UNEP, GIZ, FAO), international NGOs, expert members such as research, institutions and universities, as well as farmer organisations that although are not members are still locally involved.

Identified Challenge

The platform was created in response to the shortfalls and pressure of rice production af fecting livelihoods and the environment. With the increase in demand for rice, this is a critical issue for global food security and climate change, both on the SDG agenda. The platform allows for collaboration between partners in the public and private sector and the NGO community.

The platform was summoned by UNEP and the International Rice Research Institute in 2011. It was launched in order to promote the adoption of sustainable clime-smart best practices, as well as protecting the environment by boosting the use of resources (i.e. water, agrochemicals).

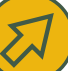

Intentions and Aspirations

The platform intends to increase sustainability in rice production as well as improve livelihoods. The platform has a mission to "promote the resource efficiency and sustainability in the global rice sector through an alliance" that links stakeholders in the value chain. The platform adopted the 2035 vision of success by the Global Rice Science Partnership (GRiSP). This incorporates; expenditures of rice by those under the $\$ 1.25$ poverty line to decline, higher food availability as a result of increased availability and reduced prices as well as the reduction of $\mathrm{CO}_{2}$ emission.

The main objectives of the platform are; pursuing pubic policy development and enable voluntary market

transformation initiative to all actors in the global rice sector. The goal is to develop a context for sustainable rice production, leverage supply chain mechanisms and public policy development as well as establish a recognised global platform. By the end of 2016, the platform aims to have adopted sustainable best practices in rice through supply chains of sustainability stand ards and practices. It aims to do so via its guiding principles including; improving livelihoods, meeting consumer needs for food security, safety and quality of rice products, effective management of natural resources as well as protecting the environment and neighbouring communities. In addition, to mitigation of GHG, being climate change conscious, as well as respecting labour rights and good business conduct.

g trust among parties;

(iii) providing a learning platform through openly sharing information; (iv) leaving the Partnership open to new members if similar risk sharing methodologies are adopted. Activities of the Secretariat hosted by UNEP's Regional Office for Asia and the Pacific in Bangkok and is overseen by an Advisory Committee, chaired by UNEP and cochaired by IRRI. There are annual meetings to elect a new Advisory Committee members as well as reviewing progress and annual programs and budget.

In order to become a member in the SRP, organisations must commit themselves to the ideology (mission, objectives, activities) of the platform. Prospected members must also contribute financially, or via their specialised resources and institutional capacity. Moreover, they requires to develop and implement in their own organisation plans to support the platforms ideology, communicate and support the SRP's process and implementation of projects whilst adhering to its guidelines. Additionally, they must operate in a transparent manner, especially towards the Secretariat, complying with SRP rules and regulations regarding external communication and the use of the platforms materials (i.e. logos). Finally, prospected members must ensure that all external communication is agreed first by the SRP Advisory Council through transparency and consensus-based decision-making.

The secretariat, which is managed by the SRP Coordinator, supports the Advisory Committee and the Working Groups, as well as the administration and coordination of the platform's operations. The annual membership fees fund the core activities of the platform. Project activities are funded from funds raised by member subscriptions as well as institutional project funding through bilateral institutions and governments.

\section{Arrangements} and Capacities

The platform provides core activities to the members including; collaborative initiatives to overcome challenges (esp. smallholder farmers), cost saving via collaborative research, access to high-level global forum for discussion and networks and institutions at the national, regional and global level regarding the rice value chain. Members will also gain recognition on the SRP website.

Moreover, core products are presented including access to tools and partnerships in order to manage social and environmental risks in the rice supply chain, as well as open access to the platform's materials and databases online at the platform's website.

Monitoring and Evaluation

The Working Group is in charge of testing and developing the guidelines, standards, tools and models for the production of sustainable rice and the development of impact indicators. As of now, the platform is focused on three interlinked instruments; (1) Guidelines for Sustainable Rice Cultivation, Performance Indicators for Sustainable Rice Cultivation, and (3) Standard for Sustainable Rice Cultivation. 


\section{(34) Tanzanian Agricultural Partnership}

\section{魚 \\ General Information}

Initiated in 2005

The Tanzanian Agricultural

Partnership (TAP) started as a Public Private Partnership, which uses a Value Chain Approach in order to improve production and marketing of agricultural goods. Based in 95 districts in Tanzania, the platform focuses on crops determined by the district stakeholder, however the platform is promoting sunflower and cassava value chains.

Members and Funds: The platform involves an international fertilizers company (Yara International), the Tanzanian Government, the Norwegian Investment Fund for Developing Countries (Norfund), the Norwegian Agency for Development Cooperation (Norad), and district based 20,000 farmers. Norad committed a grand of $\$ 2.7$ million to the platform.
Identified Challenge

The Tanzanian Governmen created the platform in order to address inefficient agricultural supply systems as well as the lack of collaboration between the government and markets. The platform allows for the coordination of activities or organisations between 25 districts where needs are met through a systematic initiative. The platform expanded to 56 districts in 2011 via a national rollout plan, and aims to ultimately cover the entire country.

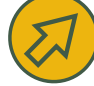

Intentions and Aspirations

The platform aims to improve the production and marketing of agricultural goods with the objective/goal to increase the accessibility/ affordability of agricultural inputs for the farmers of Tanzania, to improve the output market linkages as well as profitable agricultural production.

Moreover the platform aims to stimulate the presence of private sector investment and create a benchmark for best practice.

In order for TAP to achieve its goals it introduced factors to the strategy of Tanzanian development; enabling PPPs to facilitate the development process, using the whole value chain in order to allow for coordination, identify activities, roles and responsibility as well as sharing risks between all stakeholders. Lastly, the platform promotes transparency for th Tanzanian farmers.

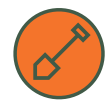

Activities and Outputs

No information available
Activities and Products

The core activities, products and services, aim to facilitate agricultural production in Tanzania. TAP delivers core activities to its members including the Farm Inputs

Promotion (FIPs) aiding the demand for inputs in 13 districts. Moreover the platform obtains a news page on the website for all members and external viewers to view as well as an events page

where regular events are held. Core products include over 25 warehouses to be renovated and built. In addition, the core services aligns FIPs with the Farmer Inputs Retaile training programme, as well as coordinating value chain support.
Monitoring and Evaluation

No information available 
$<$ Website

\section{量 General Information}

Crop: None

Geographic Scope: Global

Initiated in 1996

The Global Forum on

Agricultural Research is

a community working

collaboratively to transform

and strengthen agrifood

research and innovation

systems globally.

Active Countries:

Global

Members:

Private sector (Pan

African Agribusiness and

Agroindustry Consortium,

Croplife International, the

Sustainable Agriculture

Initiative); public-private

partnerships such as

the African Agricultural

Technology Foundation

and the Alliance for a Green

Revolution in Africa; donors

(bilateral and multilateral

donor agencies, development

banks, and philanthropic

foundations), civil society (the

Civil Society Organization

Group on Agricultural

Research for Development

(CSO GARD)), farmers'

organizations (66 national

farmers' organizations,

the Asian Farmers'
Association for Sustainable

Rural Development as a

partner in GFAR with 17

farmers' organization in 13

countries); others (the Global

Confederation of Higher

Education Associations

for the Agricultural and

Life Sciences (GCHERA),

Association of International

Research and Development

Centers for Agriculture

(AIRCA), FARA, AARINENA,

APAARI, CACAARI, EIFARD,

FORAGRO, and Global Forum

on Rural Advisory Services,

Consumers International)

Identified Challenge

Inefficient agricultural systems

The GFAR, created by the Food and Agriculture Organization (FAO) of the

$\mathrm{UN}$, and the International

Fund for Agricultural

Development (IFAD), brings

together multistakeholders at the global level to stimulate regional and national actions towards the commonly agreed aims.

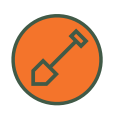

Activities and Outputs

Establish a platform for agencies and

organization to come

together to exchange

dialogue and represent

the agricultural

innovation community globally

The platform makes

efforts towards resource-

poor farmers and rural

communities, aiming to

contribute to reductions in

poverty and malnutrition and

to ensure the sustainable use

of resources. The platform

envisions making agrifoods

research and innovation

systems more effective

towards SDGs, and has a

mission to catalyze collective

actions that strengthen and

transform agrifood research

and innovation systems via

partners at all level.
The platform is governed by a partner assembly

made up of global partners, regional partners, and

partners nominated by regional constituencies. The multistakeholder steering

committee consists of

global and regional partners from other constituencies,

which are selected by the

partner assembly and

oversee accountability in all

areas of the platform. The

secretariat provides support

to the partner assembly, the

steering committee and all

stakeholders, and oversees the

development for a strategic

agenda for agrifood research

and innovation, promoting

networks and partnerships

and convening meetings.
Arrangements and Capacities

The GFAR provides its

members with main

products including a

forward-thinking platform

(a space for exchanging

and conversing about the

futures of agriculture and

rural development), foresight

working groups (for those

who wish to improve their

knowledge through active and

regular contributions), and

foresight exchange workshops

(which facilitate direct

interactions among group

members, where results,

methods, and discussion of

field experiences are shared.
Monitoring and Evaluation

The platform's steering committee is in charge of

monitoring the development of the programs, and

periodically brings in an external evaluation to assess progress, coupled with the goals and objectives. However, a monitor, learning, and evaluation approach for key outcomes is under development; this intends to document institutional and individual achievements, as well as capacities, and will improve the quality of reporting. 


\section{(i) \\ General Information}

Created in 2012 The Tropical Forest Alliance (TFA 2020) Public-Private Partnership (PPP), is a global partnership aiming to remove deforestation from palm oil, beef, soy, pulp and paper production, thus preserving tropical forests.

Members and Funds: The members of the platform derive from international private sector members (multinationals). Moreover, international government members are also involved including the government of Cote d'Ivoire, Ghana, Netherlands, Norway, Indonesia, Liberia, United Kingdom, and the United States. There is also a very strong presence of NGOs and Civil Society organisations from multiple preservation and development sectors. founded by the Consumer Good Forum (CGF) and the US government at the Rio+20.

A report published by the IPPC states that deforestation is linked to $10 \%$ of global green house gases emissions, and forests are extremely important to food security, waster security and livelihoods. The platform intends tackles the issue of the urgency to mitigate climate change, and create measures to enable food security as well as livelihoods. This is correlates to the importance of conserving and restoring forests in the SDGs. The platform aims to tackle these issues by fostering crosssector collaboration between stakeholders.

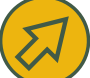

Intentions and Aspirations

The platform targets those involved in the forestry supply chain in order to restore forest, reduce GHG and improve livelihoods. The platform's mission is to enable its partners to take action, individually and collaboratively shared knowledge and best to reduce tropical deforestation associated with the sourcing of commodities (palm oil, soy, beef, paper and pulp) by tackling the drivers of tropical deforestation via market, policy and communication approaches.

and its partner

and its partner countries,
civil society and companies to work collaboratively in order to; improve the planning and management related to the issue of tropical forest conservation, agricultural land and land tenure, practice practices with each other as well as smallholder farmers and other producers of sustainable agricultural intensification, providing expertise and knowledge in order to achieve the overall platform goal, and improving the monitoring of tropical deforestation and degradation to measure the progress of the platform.

The strategy the TFA 2020 echoes the objectives of the platform to achieve its goals and supports for its partners to take voluntary as well as collaborative action to reduce tropical deforestation as well as sharing information, help facilitate relationships between partners as well as connective partners via email, telephone and other means of communication as well as at meetings or informal discussions. The platform also uses collaboration between partners to share best practices, provide expertise and knowledge support activities that help avoid tropical forest deforestation.

The role of the Secretariat is to act as a neutral coordinating platform, which coordinates and facilitates the alliance. It does so by bringing together companies and government partners to help analyze the economic potential of public and corporate no-deforestation policies, in order to catalyze projects and initiatives in countries and amongst the supply chain. The goal of the Secretariat can be grouped into three dimensions; convening stakeholders (2) co-create an environment and financing mechanisms, and, (3) communicate towards high-level decision makers and practitioners.

The platform obtains a Steering Committee of 20 members, which is a subset of the General Assembly that makes management decisions on behalf of TFA 2020. It consists of; four representatives from the forprofit private sector, four from civil society organisation, eight from governments, two indigenous and local representatives, the director of the TFA 2020 Secretariat and the ex-officio secretariat host representative. The platform is directed by all its partners and will be supported and informed by the Secretariat.

core activities, products and services. In regard to activities; companies provide a market for commodities that are tropical deforestation-

free, as well as working with suppliers to enable the purchasing of these products. Moreover, They comply with legislation and regulation that supports the conservation of tropical forests. They governments engage by improving planning and governance related to tropical forest conservation, agricultural land use and land tenure.

In regards to core products, governments enable the sharing of information regarding supply chain best practices, develop support models that encourage rehabilitation of degraded lands and allows stallholders to participate in markets. Moreover, civil society provides policy and technical expertise.

The core services provided by the government are advice and technical assistance on M\&E on tropical deforestation. Civil Society provides their extensive networks to facilitation implementation, track developments and draw attention to pressuring issues, as well as reviewing progress towards collective commitments. 


\section{(i) \\ General Information}

Established in 2000 The World Cocoa Foundation (WCF) promotes sustainability globally in the cocoa sector by providing support to cocoa farmers in order to grow more quality cocoa and strengthen their communities. The platform's presence is global with specific focus in Africa, Southeast Asia, and the Americas.

Members and Funds: As an international membership organisation, the members consist of international multinationalsmany deriving from the chocolatier industry as well as the food retailer industry, international donors and agencies including development agencies from more developed nations as well as Brazil, and ministry departments and organisations. Civil Society and NGO members are also involved in the platform including the World Wildlife Fund, TechnoServe, and World Education amongst others. Moreover, international food labs and academic research members are also participants of the platform.
Identified Challenge

The challenge the platform was made in response to the lack of low productivity in the cocoa value chain, the lack of access to market information, high rate of pest and diseases, soil degradation, as well as the lack of basic education from farmer labour practices and business decisions. The platform enables these issues to be tackled via combining local and global operations and shared benefits of the platform. embers in all aspects of the supply chain, engaging with the platform's global network of cocoa sustainability experts and practitioners, discounted registration fee for the WCF annual Partnership Meeting, ability to attend WCF Membership Assembly Meetings as well as participate in member based committees such as the steering committee meetings for the platform's flagship program in West Africa.

In regards to core services, the platform allows members to;

leverage company resources by joining other members and development agencies to achieve the platform goal, to use the platform's professional staff resources in order to address issues regarding communications/media related to cocoa sustainability, and, receive bimonthly electronic newsletters.

The core services include; the reporting of results of cocoa sustainability and benefits members in different ways. For the cocoa and chocolate industry the shared knowledge will continue to be more sustainable via the development of the cocola value chain. In regards to the WCF member companies an in depth understanding to their investment towards sourcing sustainable cocoa, and for the farmers; greater productivity and communities as well as sustainable livelihoods.

Monitoring and Evaluation

CocoaMAP as well as member companies, governments and civil society partners have enabled the platform to develop and gain greater understanding of indicators of cocoa sustainability. CocoaMAP also gave the WCF the knowledge in order to assist the company members to develop a new commitment to measuring cocoa sustainability, which has now been integrated into the CocoaAction Strategy.

From this, Key Performance Indicators (KPIs) are still under development, which aims to help inform and promote sustainability at the farm level. Moreover, in order to support CocoaAction the platform is developing resources and tools in order to improve information on sustainability performance amongst the value chain. These include the CocoaAction KPIs, The WCF Farm Information Toolkit (FIT) and the CocoaMAP online KPI Dashboard. 


\section{弇 General Information}

The ZBiDF was created in order to facilitate dialogue and innovation to engage businesses, in order to directly support public private partnerships action on busines practice and development challenges.

Members and Funds: The platform consists of multi-stakeholders including business, government, donors and civil society in Zambia. Key partners in the private sector include the Zambia Association of Manufacturers (ZAM), Technical

Education, Vocational and Entrepreneurship Training Authority (TEVETA), The Private Sector Development Reform Programme (PSDRP) and the International Labour Organisation (ILO). More ove government members include the ministry of Commerce,

Trace and Industry for

Zambia as well as the Zambia Development agency. Moreover, international agencies are members of the platform including the Embassy of Sweden as well as the United Nations Development Programme. NGO and civil society is made up from the Netherlands
Developments Corporation as well as the Copperbelt University, and there is support from Private sector development organisations for Zambia.

\section{Identified Challenge}

The ZBiDF is a Business Partnership Action hub that was initiated by The Partnering Initiative (TPI) The challenge the platform aims to tackle is the lack of trust across sectors and the lack of government resources and capabilities to do so. However, through the use of local country level platform it can bring together stakeholders in order to

demonstrate to each member the alignment of interests. Moreover, it allows for the facilitation of innovation as well as developing a 'winwin' partnership between stakeholders. to tackle mistrust, 2. Assist specific divisions and individuals in business situations in order to effectively develop partnerships, and 3. Support its partners and potential collabora-

tors. Moreover, as the platform aims to obtain cross-sector collaboration a trained broker in each sector will work with all the stakeholders in order to ensure trust and overall goals of the platform. holders in agriculture as we as participating citizens in the smallholders, the platert contributes to the public good of increasing productivity, whereas for the extractive industries it aims to promote indigenous SME participation in local mine and non-mine value chains. Additionally, for the manufacturing target group the platform intends to develop a skilled human resource, in order to increase employability and productivity.

ZBiDF's mission is to support, catalyse and scale cross-sector partnerships, that allows the full potential of businesses to operate in a commercially viable manner as well as supporting development goals. The main goal/objective of the partnership is to facilitate dialogue and innovation between businesses as well as engaging them and supporting PPPs on business and development challenges.

The platform's strategy to achieve its overall mission, goals/ objectives is via three approaches; 1 . Create facilitated spaces for all members in order

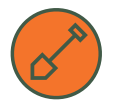

Activities and Outputs

The platform's operations and business development is managed by the National Director, with a current focus of supporting and controlling the development of partnerships in manufacturing, agriculture and extractive. ZBiDF is managed via a small team of trained 'Partnership Brokers' that act as the managers of the partnering process taking initial and follow up step to ensure collaboration is taking place. Key members of the governance structure include the Zambia Business in Development Facility that attains guidance and assistance from the Champions \& Advisory Group (CAG). The CAG is then compromised of stakeholders from differing sectors, which include international donors and organisations. Their main role is to leverage resources, promote action and provide strategic advice to the ZBiDF. rrangements and Capacities

The platform provides its members with core activities including an environment where players across sectors and industries can take action on issues of mutual benefit, assisting stakeholders to develop effective partnerships and providing assistance to those already in formed partnerships by providing technical assistance. Moreover, the platform supports partners and potential collaborators in finding ways to knowledge share their resources on issues of mutual interest.

The platform also provides its members with core services including; creating cross sector partnerships, supporting, scaling and sustaining the partnerships as well as partnership skills building and communication/ dialogue across public-private cross sector arenas. Evaluation

No information available 


\section{Colophon}

\section{Authors:}

J. Guijt, M.Maestre, J. Thorpe, S. Wigboldus and C. Ashley

\section{Citation:}

Guijt J., Maestre M., Thorpe J., Wigboldus S. and Ashley C. (2017) Structured scans of multistakeholder platforms. IDS Institute of Development Studies and Wageningen University \& Research. (C) 2017 Institute of Development Studies and Wageningen Research

\section{Acknowledgements}

We are grateful to the Rockefeller Foundation for their willingness to invest in an unknown but necessary topic to explore. We would also like to thank those who have been involved at different stages of the research conceptualisation and implementation, including particularly Caroline Ashley, Sean de Cleene, Riti Hermán Mostert, Andrew Kambobe, Mar Maestre Morales, Kavita Prakash-Mani, Don Seville and Seerp Wigboldus. We also appreciate the efforts of all the staff from MSPs who helped explore ideas and contribute to discussions, including Rafael Seixas and Sven Sielhorst from Bonsucro and Saori Kitajima and Kajsa Nyerere from Farm to Market Alliance, as well as Akim Dharmawan and Patrizia Fracassi from the Scaling Up Nutrition initiative.

Design: rco.design
Institute of Development Studies

Library Road, Brighton, BN1 9RE, UK

$\mathrm{t}+44(\mathrm{o}) 1273606261$

e ids@ids.ac.uk

www.ids.ac.uk

The Partnering Initiative

21B Park End Street, OX1 1HU, UK

$\mathrm{t}+44$ (o) 1865582248

e info@tpiglobal.org

TPIglobal.org

Wageningen Centre for Development Innovation part of the Stichting Wageningen Research

P.O. Box 88, 6700 AB Wageningen, The Netherlands

$t+31(0) 317486800$

einfo.cdi@wur.nl

www.wur.eu/cdi

This report can be downloaded for free at http://doi. org/10.18174/541809 or at www.wur.eu/cdi (under "Publications")

The Wageningen Centre for Development Innovation uses a Creative Commons Attribution 4.0 (Netherlands) licence for its reports.

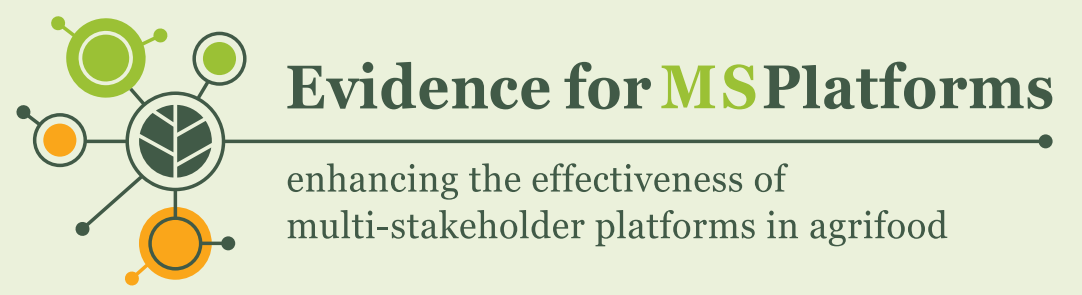

WAGENINGEN UNIVERSITY \& RESEARCH
O institute of development studies 